January 2019

\title{
"How am I going to handle the situation?" The Role(s) of Reflective Practice and Critical Friend Groups in Secondary Teacher Education
}

James R. Carlson

University of Wisconsin - La Crosse, jcarlson@uwlax.edu

Follow this and additional works at: https://digitalcommons.georgiasouthern.edu/ij-sotl

\section{Recommended Citation}

Carlson, James R. (2019) "'How am I going to handle the situation?" The Role(s) of Reflective Practice and Critical Friend Groups in Secondary Teacher Education," International Journal for the Scholarship of Teaching and Learning: Vol. 13: No. 1, Article 12.

Available at: https://doi.org/10.20429/ijsotl.2019.130112 


\title{
"How am I going to handle the situation?" The Role(s) of Reflective Practice and Critical Friend Groups in Secondary Teacher Education
}

\begin{abstract}
This qualitative study was designed as a single-case study of a small, public, teacher education program in the Midwest. The author conducted a study on the perceived role of a "critical friends group" (CFG) in the development of beginning secondary teacher candidates' understandings and practices of reflective practice. Three main types of data, including course assignments, participant interviews, and observations were collected and analyzed. Findings from three (3) focal participants reveal characteristics of reflective teaching from the reviewed literature observed within and across the cases examined here. The perceived importance of the CFG varied on a case-by-case basis, with some experiencing the CFG as friendly, but mostly uncritical, and others remaining indifferent to the arrangement. Additionally, the author elaborates on three broad lessons learned and reinforced through the investigation into the local, including: 1) Critical reflection can and does occur in beginning TCs' practice, 2) CFGs led to informative learning, but not transformative learning, and 3) Designating a group "critical friends" is neither a guarantee of critical thinking or friendship.
\end{abstract}

\section{Keywords}

Reflective Teaching, Critical Reflection, Critical Friends Group, Teacher Education

\section{Creative Commons License}

(c) (i) $\ominus$

This work is licensed under a Creative Commons Attribution-Noncommercial-No Derivative Works 4.0 License.

\section{Cover Page Footnote}

This research project received generous support from the office of the Provost of the University of Wisconsin - La Crosse and UW System's Office of Professional \& Instructional Development's (OPID). 
IJ-SoTL, Vol. 13 [2019], No. 1, Art. 12

\title{
Beginning Secondary Teacher Candidates and Reflective Teaching: The Role of a Critical Friends Group
}

\author{
James R. Carlson
}

University of Wisconsin - La Crosse

Received: 2 March 2018;Accepted: I October 2018

\begin{abstract}
This qualitative study was designed as a single-case study of a small, public, teacher education program in the Midwest. The author conducted a study on the perceived role of a "critical friends group" (CFG) in the development of beginning secondary teacher candidates' understandings and practices of reflective practice. Three main types of data, including course assignments, participant interviews, and observations were collected and analyzed. Findings from three (3) focal participants reveal characteristics of reflective teaching from the reviewed literature observed within and across the cases examined here. The perceived importance of the CFG varied on a case-bycase basis, with some experiencing the CFG as friendly, but mostly uncritical, and others remaining indifferent to the arrangement. Additionally, the author elaborates on three broad lessons learned and reinforced through the investigation into the local, including: I) Critical reflection can and does occur in beginning TCs' practice, 2) CFGs led to informative learning, but not transformative learning, and 3) Designating a group "critical friends" is neither a guarantee of critical thinking or friendship.
\end{abstract}

\section{INTRODUCTION}

Adults working and learning together in thoughtful ways has been demonstrated to improve practice and improve student learning (Bryk, 2010; Capers, 2004; Danielson, 1996; DuFour, DuFour, Eaker, \& Karhanek, 2004; DuFour \& Eaker, 1998; DuFour, Eaker, \& DuFour, 2005; Fahey \& Ippolito, 20I4; McLaughlin \& Talbert, 2006; National School Reform Faculty, 2012). The adoption and implementation of professional learning community or PLC structures in many school districts, in premise, enables teachers to understand their work as/within an interdependent network of others (e.g., colleagues, school, district) and to collaboratively come to grips with dilemmas of practice and pedagogy (Burke, Marx, \& Berry, 20 I I; DuFour \& Eaker, 1998). Though PLCs and the closely-related Critical Friends Groups (CFGs) are often touted as powerful group learning methods for empowering instructional practices at the individual and group level, few professionals, as a result of their teacher preparation, have been adequately prepared for the transition from an intrapersonal construction of instructional practice (e.g., reflecting in a paper on a lesson) to the interpersonal model (e.g., reflecting in a group on one member's teaching) (Burke, Marx, \& Berry, 20 I I; Darling-Hammond \& Bransford, 2005). Indeed, in the literature (and even film), effective teaching is constructed as a solitary, soul-searching, test of survival (Ayers, 1993; Beyerbach, 2010).

While DuFour, Eaker, \& DuFour (2005) provide evidence that PLCs are a more preferable form of professional development for adult learners than the traditional format (e.g., didactic, "sit-and-get"), this deviation from the traditional (e.g., top-down) delivery of professional development presents new and unprecedented expectations for teachers (Burke, Marx, \& Berry, 20I I). Evidence exists that professionals working together can lead to good things (e.g., improved practice, student learning); however, less is known about how adults learn to share their practice, to give and receive useful feedback, and to be reflective (Fahey \& Ippolito, 20I4). Mindrich \& Lieberman (20I2) refer to the plethora of research on the implementation of adults working and learning together in community, particularly on the importance of factors such as trust and leadership (Bryk \& Schneider, 2002; Elmore, 2000). Less robust in the literature, however, are the ac- counts of how to create community while working toward changes in practice.

The seeming simplicity of Critical Friends Groups (CFGs) in school reform has attracted educators and educational leaders working to improve professional practice and student learning (Fahey \& Ippolito, 20I4). As Fahey and Ippolito (20I4) contend, the supposedly uncomplicated structure of CFGs "assumes that teachers have both things to learn from each other and things to teach each other, and that learning together will improve their teaching practice, deepen their knowledge of students, and build a shared understanding of fundamental ideas about schooling" (p. I). Despite its attraction as a simple solution for educational reform, CFGs are far more complex than the initial impression. Among a long list of factors that potentially influence CFGs, the following also may impact CFGs, including: the focus of the CFG, size and stability of the group, membership of the group, availability of time to meet, reason for being there, the facilitation skills of individuals in the group, the support or perceived support from group members and even educational leader(s), and even the culture of the school/program/community.

Prior to this interventions, as part of their initial field experience at "River City University" (RCU) (a pseudonym), secondary pre-service teacher candidate (TC) preparation more closely reinforced an interpersonal construction of reflective practice than an intrapersonal, more social and collaborative construction of reflective practice. As an example of the interpersonal construction, reflective teaching journals submitted for a course assignment in the researcher's classroom had always been considered "private" rather than "public" (Foster, 20 I5; Jones \& Ryan, 20I4; Sturgill \& Motley, 20I4). That is, TCs submitted their journal entries (see Appendix A for guiding prompts) to the online management "dropbox" or repository and the instructor/researcher provided individualized feedback on content and quality of reflection.

While private journals - which have no readership other than the instructor - have been shown to compel personal/emotional risks, other more public formats (e.g., semi-public blog) for reflection have been found to authorize students to take more intellectual/logical risks (Foster, 2015). As the researcher sought 
ways to foster TC reflection, it became apparent that the private reflective journal assignment - while providing space for personal risks - limited more open, collaborative, and cooperative conversations about teaching and learning (Osterman \& Kottkamp, 1993). In an effort to support TCs in gaining experiences for reflecting in collaboration with others, the researcher began an investigation into (I) how beginning TCs understood and practiced teacher reflection and (2) how or if a critical friends group (CFG) would support TCs as they engaged in critical reflection in their journals.

\section{RESEARCH QUESTIONS}

This study addresses the following research questions:

I. How do beginning secondary TCs at RCU, in their first supervised practicum experience, understand the concept of reflection?

2. (How) does a reflective teaching journal help beginning TCs engage in critical reflection?

3. (How) does a CFG support beginning teachers to become critically reflective in their journals?

\section{REVIEWED LITERATURE What is Critical Reflection?}

Reflective teaching is a cornerstone of teacher preparation and teacher development programs (Calderhead, 1989; Fendler, 2003; Flessner, 20I2; 20I4; Flessner, Miller, Patrizio, \& Horwitz, 20I2; Foster, 2015; Hatton \& Smith, 1995; Myers, 2012; National Council for the Accreditation of Teacher Education, 2010; Sturgill \& Motley, 2014; Zeichner, 1992; 1996). It would be impossible to find a teacher education program/educator dismissive of cultivating reflective practice (Zeichner \& Liston 2013). Despite ubiquitous standing as a guiding principle in teacher education, there is no singular or unified definition of reflective practice (Rodgers, 2002).

John Dewey has played a crucial role in guiding educators with a definition of reflective teaching. According to Dewey (1933), reflective thinking or inquiry is the result of "active, persistent, and careful consideration of any belief or supposed form of knowledge in the light of the grounds that support it, and the further conclusions to which it tends"'(p. 6, emphasis in original). For Dewey, reflective thought is the result of considering consequences of one's actions, not just the chronological sequence. Dewey reasoned the reflective process is set in motion by an experience, a dilemma, or by "puzzles of practice” (Munby \& Russell, 1990). Prompted by feelings of uncertainty, teachers step back, often in the midst or after action has wrapped up, and analyze the situation and their experiences. However, not all thinking is necessarily reflective, and Dewey distinguished between routine action and reflective action. According to Dewey, unreflective teachers have lost sight of the purposes and ends of education as they become agents of others' ways of responding to a given situation (e.g., authority, tradition). In contrast to the unreflective teacher whose routine action is guided by taken-for-granted assumptions about students and learning, Dewey argued reflective teachers carefully consider particular beliefs and/or practices through multiple dimensions (e.g., personal, academic) and lenses (e.g. technical, practical, critical).

Similar to any approach to reflection, critical reflection must be seen as a political act, with adherents fluidly progressing from the personal and academic dimensions of teaching to include the social/political dimensions of teaching (Calderwood, Mazza, Clarke, Favano, Jean-Guillame, McNeill, \& Stenerson, 2008; Yost, Sentner, \& Forlenza-Bailey, 2000). Drawing comparisons between the terms reflection and critical reflection, Hatton and Smith (1995) note that both terms appear to have a wide variety of meanings and application. For some, critical reflection means constructively self-criticizing past actions with focus on improving future teaching. Others argue for a more nuanced conception, moving beyond self-criticism to include consideration of cultural and institutional contexts of teaching and learning. Liu (20I5) provides teacher education with a comprehensive definition for critical reflection which accounts for the tensions embodied in the concept.According to Liu (2015),

Critical reflection is a process of constantly analyzing, questioning, and critiquing established assumptions of oneself, schools, and the society about teaching and learning, and the social and political implications of schooling, and implementing changes to previous actions that have been supported by those established assumptions for the purpose of supporting student learning and a better schooling and more just society for all children. (PP. I44-I45)

Drawing from Liu's definition, in practice, critical reflection promotes risk-taking, both intellectual risks (e.g., taking a stance for a just society) and personal risks (e.g., acknowledging misconceptions) (Foster, 20 I 5; Lee, 2005; McDonald \& Kahn, 20 I4). Furthermore, critical reflection involves questioning common practices in schools, including, for instance, ability grouping, tracking, disproportionality and overrepresentation issues, gender binaries, behavior control, and competitive grading (Artiles \& Bal, 2008; Miller, 2015; Sparks-Langer, 1992). As Liu's definition suggests, critical reflection involves clarifying individual beliefs while also examining hidden curriculum and teaching practices for lessons about power and equity (Anyon, 1980; Christensen, 2017). While individual achievement has been emblematic of teacher reflection, critical reflection is more commonly conceived as nourished in supportive and collaborative settings of critical friends, as it is argued that individuals gain clarity in understanding by sharing with others and learning from perspective-taking (Francis, 1995; Solomon, 1987).

Critical reflection is further conceptualized as a complex and fluid process of moving inward (personal and biographical dimensions) and outward, (institutional, cultural, and political contexts of teaching) with individual and group analyzing, questioning, and critiquing (Flessner, Miller, Patrizio, \& Horwitz, 20I2; Liston \& Zeichner, 1990; Valli, 1993; Zeichner, 2008; Zeichner \& Liston, 20I3). Indeed, Schön's ( 1983) groundbreaking work on reflective practice has been the subject of critique for its emphasis on the individual and limited attention to the social conditions framing and impacting practice (Zeicher \& Liston, 20I3). In contrast to Schön's condoning of "a submissive response to the institutional conditions and roles in which teachers find themselves" (Zeichner \& Liston, 2013 p. 20), Zeichner and Liston (2013) argue, "teachers should be encouraged to focus both internally on their own practices, and externally on the social conditions of their practice, and ... their action plans for change should involve efforts to improve both individual practice and their situations" (p. 20). A defining characteristic of critical reflection, then, is the dialogical nature of reflection. 


\section{Traditions of Reflective Practice}

Liston and Zeichner (I99I), Tabachnick and Zeichner (199I), Zeichner and Liston (2013) catalogue a variety of orientations or traditions of reflective practice relevant to reform efforts in teaching and teacher education. Zeichner and Liston (2013) situate the following diverse traditions of reflection: progressive, conservative, social justice, and spiritual-contemplative. Each tradition focuses on what teachers might emphasize in their teaching and different aspects of expertise in teaching (see Table I).

\begin{tabular}{|l|l|l|}
\hline \multicolumn{2}{|l|}{$\begin{array}{l}\text { Table I. Reflective Traditions and their Emphases } \\
\text { (based on Zeichner \& Liston, 20 / 3) }\end{array}$} \\
\hline $\begin{array}{l}\text { Reflective } \\
\text { Tradition }\end{array}$ & Emphasis & Description \\
\hline Progressive & $\begin{array}{l}\text { Child- } \\
\text { Centered }\end{array}$ & $\begin{array}{l}\text { Ask us to see learning and schooling } \\
\text { from the child's perspective }\end{array}$ \\
\hline Conservative & $\begin{array}{l}\text { Content- } \\
\text { Centered }\end{array}$ & $\begin{array}{l}\text { An approach to teaching that empha- } \\
\text { sizes knowledge and skill acquisition }\end{array}$ \\
\hline Social Justice & $\begin{array}{l}\text { Context- } \\
\text { Centered }\end{array}$ & $\begin{array}{l}\text { Advocate for schools as an engine } \\
\text { for social change; disruption of status } \\
\text { quo; mindful of inequalities in school } \\
\text { structure }\end{array}$ \\
\hline & $\begin{array}{l}\text { Contemplative- } \\
\text { Centered }\end{array}$ & $\begin{array}{l}\text { Focusing on the "aha" moments; } \\
\text { emotions in teaching are explored, } \\
\text { not discarded; questions of head, } \\
\text { heart, body, \& soul }\end{array}$ \\
\hline
\end{tabular}

According to Zeichner \& Liston (20I3), the hallmark of the progressive, or child-centered orientation, is its focus on the child and a meaningful curriculum whereby students' interests and backgrounds, combined with their developmental progression, are foregrounded.The conservative tradition, or content-focused/ academic tradition, underscores a style of reflection focused on knowledge and skill acquisition, with an emphasis on the application of teaching strategies.

The social justice tradition places emphasis on social and political contexts of schooling and assesses a commitment to enhancing equity and justice in schools and society. Proponents of the social justice tradition attempt to highlight the discrepancy between promises of a public education in the U.S. with actual harms of public schools (e.g., institutional racism, sexism, etc.).

Lastly, the spiritual-contemplative tradition captures and situates those moments in teaching when we experience wonder and beauty (e.g., breathtaking 'aha' moments), as well as those moments in teaching when we experience pain and heartache (e.g., a student whose parents are separating).

\section{What are "Critical Friends"?}

The notion of critical friendship "is grounded in the belief that teachers of all levels can mentor and support one another" (Franzak, 2002, p. 278). Critical friend groups (CFGs) have been defined as a network in which teachers collaboratively inquire into their practice and student learning (Costa \& Kallick, 1993; Franzak, 2002; Nieto, 2000). CFGs provide participants with opportunities to engage in dialogue, to collaborate, to question, and to productively challenge one another in an environment that encourages reflection on teaching practice, as well as in terms of broader ethical and moral dimensions (Hatton \& Smith, 1995 Pultorak, 1996).
A critical friend is someone, or some small group of people, who provide feedback to individuals exploring "puzzles of practice" (Munby \& Russell, 1990, p. 72). According to Costa and Kallick (1993),

[a] critical friend ... is a trusted person who asks provocative questions, provides data to be examined through another lens, and offers critique of a person's work as a friend. A critical friend takes the time to fully understand the context of the work presented and the outcomes that the person or group is working toward. The friend is an advocate of that success. (p. 50)

At the center of critical friendship is a habit of engaging in systematic reflection on teaching practices and learning outcomes (Bambino, 2002). Francis (1995) makes the case that individual reflection is enriched by group and partner collaborations. In a profession that can be as isolating as it is demanding (Dana, 20 I3; Franzak, 2002), critical friends provide teachers with a network of supportive and encouraging collaborators. Such friends value the dialogical nature of teaching that benefits from personally directed professional learning (Myers, 20I2).

\section{RESEARCH METHODS}

As a way to better understand the impact of CFGs on beginning TCs' understandings and practices of reflective practice, the researcher gained approval through RCU's Institutional Review Board (IRB) to conduct research that was qualitative by design.A qualitative approach provided opportunities for considering the lived experiences and realities of the participants in ways that may have been less accessible through other qualitative and/or quantitative research methods (Glesne, 2006). The project relied upon traditional qualitative methods of data collection, including the generation, collection, and analysis of documents, interviews, and observations (Creswell, 2007).

\section{Design}

This qualitative study was designed as a single-case study in order to draw upon the rich sources of data existent in the classroom environment (Merriam, 2007; Yin, 20I7). The case studied involved a small, public, liberal arts university teacher education program that bound participants in the common endeavor of becoming future teachers and in the common experience of an initial field practicum and accompanying course. The participants were analyzed individually in order to better understand individual experiences within a shared milieu.

Case study provided the researcher with opportunities to collect a broad spectrum of data and analyze multiple participants over an extended period of time (Patton, 20I5; Yin, 20I7). The researcher used a case study approach in order to better understand participants' conceptions and practices of reflective practice and to better understand the role of a critical friends group in contributing to reflective practices. Through the use of interviews and other sources of data, case study provides participants a forum to "tell their own stories" (Tannebaum \& Cridland-Hughes, 2015).

This research seeks to provide findings relevant and applicable to teacher education, writ large. In order to present valid and reliable conclusions, the researcher studied the cases of multiple participants (Merriam, 2007; Patton, 20I5). To ensure credibility, the researcher triangulated the data using multiple methods 
and comprehensive data sources (Anney, 20I4; Lincoln \& Guba, 1985; Shenton, 2004). In addition, the researcher relied on the technique of member-checking, sharing with the participants, transcripts and initial interpretations of the data and providing participants with opportunities to clarify intentions, correct mistakes, and contribute additional information if necessary.

As the instructor/supervisor and as a participant observer, it is important to acknowledge the role of ethics in collecting, analyzing, and disseminating qualitative data (Pedro, 2005; Stake, 1995). As a "guest in the private spaces of the world" (Stake, 1995, p. 44; in Pedro, 2005, p. 55), qualitative researchers must adhere to an upstanding code of ethical standards. The researcher is aware of the multiple and competing roles at play in this representation of findings. The researcher's own social and theoretical positions, along with personal biases, certainly influenced the filtering and analyzing of the data (Merriam, 2007; Pedro, 2005).

\section{Setting}

This study occurred in the fall of 2017 and took place in a junior-level introductory general methods (literacy-emphasis) course in a small, public university in the Midwest. The course is the first of two field-based methods courses taken by preservice teachers in the secondary education program at RCU. In addition to serving the secondary education program, the course serves a smaller, arts-based teacher-education program which prepares teacher candidates as future music, art, and global/world language teachers. While the secondary certification track leads to an endorsement to teach grades 6-12, the arts-based tracks lead to a $\mathrm{K}-\mathrm{I} 2$ license. Referring to the participants as "secondary" is a bit of a misnomer, because in fact, the art, music, and global/world language candidates could be future "secondary," "middle," "elementary" (or some combination within) teachers.

$R C U$ is a small public university with enrollment hovering around 10,000 students, mostly undergraduates ("RCU" Fast Facts, 20I4). The university is situated in a mid-sized, Midwestern city, with a population of approximately 55,000 (U.S. Census Bureau, 2010). The campus is composed of predominantly white students $(90 \%)$ and approximately $25 \%$ of the undergraduate student body is considered low-income. The teacher education program at RCU is reflective of current demographic trends in the teaching force: mostly white, female, middle-class, and monolingual.

The participants in the course pertaining to this study are often concurrently enrolled in child/adolescent growth and development courses, and they have completed previous coursework in foundational education courses on the History of Public Education, Multicultural Education, and Education in a Global Society. The teacher education program promotes values ascribing to the preparation of "globally responsive" teachers and has demonstrated commitments to a robust clinical preparation in a Professional Development School (PDS) model for teacher preparation. A PDS is a partnership between a K-12 school/ district and university aimed at developing and supporting professional learning and knowledge through inquiry, mentoring, and critical reflection (Zeichner, 2007).

The 4-credit course used as the context for this study met once a week for 175 minutes (approximately three-hours). In addition to weekly course meetings, over the course of a traditional 15-week semester, students enrolled in the course were enrolled in a concurrent field experience in a public classroom assigned to them by the program. The researcher served as the instructor for the course and supervisor of the practicum during the semester under study.

For this course and embedded field, teacher candidates are placed at a local Professional Development School (PDS), where they work closely with a mentor teacher in their content area (a licensed teacher who agrees to mentor the teacher candidate). For this initial field experience (candidates have a second semester-long field experience followed by a student teaching semester), TCs commit 3-4 hours/day for 3-4 days/week at their site for approximately 100-120 hours throughout the semester. As part of the field experience,TCs are required to teach three lessons under the guidance and supervision of their mentor teacher and serve as a support to the mentor teacher.

The participants in this study were placed at two sites in two different districts, one suburban and one rural. In the fall of 2017, enrollment in the two sections of the course totaled 29 (16 in Sec. I; 13 in Sec. 2). Students were assigned by the instructor/researcher to a CFG (4-5 students per group) in their respective section (4 groups of 4 in Sec. I; 2 groups of 4 and I group of 5 in Sec. 2). Each CFG comprised, as much as possible, of a diverse group of teacher candidates in terms of gender, content area, and PDS placement. The groups were selected by the researcher/teacher at beginning of the semester.

In the syllabus, the CFG was outlined as a group dedicated to supporting and challenging one another in an environment that encourages reflection on teaching practice. The syllabus referred to one main "assignment" for the CFG, which outlined the expectation that each bi-weekly reflective teaching entry (total = 4) be uploaded/made available to the CFG on the course online platform. The syllabus stated,

For each reflective teaching entry submission deadline, you are responsible for reading and providing written feedback to at least one (I) member of your group on [course online instructional platform] for your friends group. You will have time in class to further debrief and connect with one another on your reflective teaching entries.

In practice, during face-to-face course meetings, CFGs met weekly for 20-25 minutes for an unstructured debriefing on the field component of the course and to provide opportunities for individuals to elaborate and seek feedback on their field experiences. In addition to the CFG, TCs in the course spent time in class working in other small pods or groups (e.g., content-alike groups; instructional routine instruction group). For the CFGs, TCs were instructed to provide formative feedback to their peers on their reflective teaching entries and in-class contributions, but they were not peer-evaluated or instructor-evaluated for their performance through any formal instruments or measures.

\section{Participant Selection}

Eighteen (18) teacher candidates signed consent forms to participate in the study. However, due to the timing of the scheduled interviews, in late December when students typically go home for winter break, many participants were unavailable to participate in the interview portion of the project. The researcher eventually interviewed 9 teacher candidates at the conclusion of the fall semester, in December 2017 and January 2018, after final course grades were posted. See Table 2 for additional information about participants, their content areas, and placement information. 


\begin{tabular}{|l|l|l|l|l|l|}
\hline \multicolumn{6}{|l|}{ Table 2. Participants at a glance. } \\
\hline $\begin{array}{l}\text { Participant } \\
\text { (Pseudonym) } \\
\text { \& Gender }\end{array}$ & Age & $\begin{array}{l}\text { Content } \\
\text { Area }\end{array}$ & Placement & Section & Group \# \\
\hline Austin (M) & 23 & Science & Suburban & I & 4 \\
\hline Dustin (M) & 20 & ELA & Suburban & I & I \\
\hline Molly (F) & 22 & ELA & Suburban & I & 3 \\
\hline Angie (F) & 21 & ELA & Rural & I & 4 \\
\hline Megan (F) & 2 I & Science & Rural & $\mathbf{2}$ & $\mathbf{6}$ \\
\hline Ericka (F) & $\mathbf{2 I}$ & Spanish & Suburban & I & $\mathbf{2}$ \\
\hline Alex (M) & 20 & History/SS & Rural & 2 & 7 \\
\hline Ellen (F) & 21 & ELA & Rural & 2 & 7 \\
\hline \multicolumn{7}{|l|}{ Rose (F) } & 2I & ELA & Suburban & I & I \\
\hline Note: Bolded participants are situated in this paper. \\
\hline
\end{tabular}

The participants for this study constitute a "convenience sample" (Creswell, 2007), or a sampling of participants who were selected due to their proximity and accessibility to the researcher In terms of criteria for selecting the participants presented here, the researcher sought to bring into contact together a range of dimensions, perspectives, and formats represented in the participant pool. The participants situated here offer opportunities to examine instances of convergence and divergence in terms of dimensions of reflective practice, perspectives on the friend groups, and formats of submitted work. Secondly, for this paper, the researcher sought to situate perspectives from a diversity of content areas. The three participants situated (Rose, Megan, \& Ericka) represent a diversity of the content areas (ELA, Spanish, \& Science) represented in the cohort. At the same time, they are reflective, overall, of the demographics of teacher candidates in the program (e.g., white, middle class, female). Another criterion for selection in this exploration was a diversity in practicum placement settings. The participants presented here were placed in practicum sites representing differing locations, including suburban and rural settings. A final criterion for selection in this exploration was to obtain perspectives from a cross-section of the CFGs in the class. The three participants featured represent a cross-section of the CFGs.

\section{Limitations and Research Subjectivities}

Although this research has been carefully prepared, it is important to acknowledge the shortcomings and limitations of its design and impact. First, this research was conducted across two sections of a I5-week course offered at a single teacher education institution in the Midwest. Additional time for longitudinal data to be collected across multiple semesters would improve the overall clarity and significance of the findings. While this study situates three TCs' experiences over the course of one semester (early in their career path), following participants over a greater period of time and in changing settings would provide for more robust results. For instance, what would the participants' perspectives on reflective teaching look and sound like at the end of their second practicum? How would their ideas about critical friends and reflective practice look and sound like during their student teaching experiences, or even at the height of their submissions of the high-stakes Educational Teacher Performance Assessment (edTPA) portfolio required for graduation and cer- tification? As well, (how) would these beginning TCs' practices of/for reflection evolve over the course of their first few years in teaching?

In addition to the limitation of time, this study could benefit from examining TC perspectives across multiple, geopolitically diverse teacher education programs and institutions. For example, in what ways would the perspectives of TCs from River City be similar to and/or vary from other regions of the U.S., and in what ways do these perspectives vary from candidates in various international contexts? In addition, while the researcher gathered baseline data from a variety of participants, the focus of this paper is limited to an analysis of three participants' experiences with and opinions toward the CFG. In terms of gender alone, noticeably absent from the discussion in this paper are perspectives from teacher candidates who do not identify as female, including perspectives from male, gender-fluid, and non-binary teacher candidates. While male teacher candidates were interviewed as part of this study, in a future analyses, a scrutiny of gender may provide additional insights into stances toward reflective practice. In the future, then, interviews conducted with a larger sample of teacher candidates hold potential for making additional, perhaps more pointed observations on teacher candidate understandings and practices of reflective practice.

The researcher's role as the instructor-of-record and supervisor for the course calls into focus additional limitations of this study related to the researcher's biases. As an instructor/ supervisor to the focal participants, the researcher's role as "the researcher" was not as one in traditionally or clinically defined terms. Beginning TCs who agreed to inform this study may have felt compelled to participate in this study because of the researcher's status as instructor. Inevitably, the researcher's status as an instructor impacted and/or tempered the stories narrated by the focal participants. Other aspects of the researcher's identity and socialization as white, middle-class, Midwestern, and cisgender male may have limited, altered, and/or constrained the interpretations presented.

Finally, the researcher happened upon the extensive work of National School Reform Faculty's (NRSF) Critical Friends Group $\circledR(C F G \mathbb{B})$ after piloting the inquiry into the project presented here. As a result, the definition of and expectations for a Critical Friends Group presented in this manuscript are at variance with the NSRF's definition and practices. As of this writing, the researcher has not been through the extensive professional development training offered to $C F G \AA$ coaches and facilitators through the Harmony School Education Center. A key feature of Harmony School's CFG $®$ relates to the use of protocols, or structured processes for efficient communication and problem solving. The participants in this study were not provided protocols for facilitating communication. This is a key limitation to the overall experiences of the participants situated here, as the use of more structured protocols may have provided for more of a range of experiences in the friend groups. 


\begin{tabular}{|l|l|}
\hline \multicolumn{2}{|l|}{ Table 3. Data sources and foci of the data analysis } \\
\hline Data Source & Focus \\
\hline Written documents & $\begin{array}{l}\text { Bi-weekly reflective teaching journal summarizing and analyzing class and fieldwork; analysis of attitudes, pro- } \\
\text { cess, content (main concerns), and depth of thinking }\end{array}$ \\
\hline $\begin{array}{l}\text { Reflective Teaching Journals } \\
\text { (September-December) }\end{array}$ & $\begin{array}{l}\text { Trajectory of themes (e.g., curriculum content, students, instruction, context) in low-stakes, in-class writing-to- } \\
\text { learn assignments over time (e.g., metaphors for teaching, problems of practice) }\end{array}$ \\
\hline $\begin{array}{l}\text { In-class writing-to-learn/quick writes } \\
\text { (September - December) }\end{array}$ & $\begin{array}{l}\text { Pre and Post response to the question:What does it mean to be a critically reflective teacher? } \\
\text { Comparison between pre and post responses }\end{array}$ \\
\hline Pre-questionnaire (September) & $\begin{array}{l}\text { Context of classroom, co-op, and students } \\
\text { Post-questionnaire (December) } \\
\text { Observation of prospective teacher teaching a lesson }\end{array}$ \\
\hline Observations & Observation(s) of prospective teacher's role(s) in friends group (online forum [bi-weekly] and in-class [weekly]) \\
\cline { 1 - 2 } $\begin{array}{l}\text { Field Observations } \\
\text { (September-December) }\end{array}$ & $\begin{array}{l}\text { Reflections on field experience and course/fieldwork, perceptions on the self as reflective practitioner, experi- } \\
\text { ences that necessitated reflection, experiences/importance of critical friends group in guiding reflection, goals } \\
\text { and expectations for future }\end{array}$ \\
\hline $\begin{array}{l}\text { Critical Friends Group Observations } \\
\text { (September-December) }\end{array}$ & $\begin{array}{l}\text { Interview/Survey (December) } \\
\text { Semi-structured individual interview } \\
\text { (December 20I7-january 20I8) }\end{array}$
\end{tabular}

\section{DATA COLLECTION \& ANALYSIS}

Three main types of data, including course assignments, interviews, and observations were collected and analyzed (see Table $3)$.

At semester's end, the researcher interviewed participants to gain insights into their experiences in CFGs. Interviews with 7 participants were audio-recorded and transcribed. In addition to the interviews, two participants submitted written responses to the interview prompts. In these cases, due to the timing of the semester (winter break) the participants were not available for face-to-face interviews; however, they offered to respond in writing to the interview protocol sent via email. For this paper, data analysis began with these 9 participants.

The researcher utilized a semi-structured interview protocol (see Appendix B) for conducting interviews. Participants in the interview setting may be more willing to discuss sensitive topics through a two-way conversation rather than through other, less personal data collection conduits. The semi-structured protocol provides an interviewer with more flexibility in pursuing individual story lines that emerge during the interview (Seidman, 2006). Along with providing opportunities for building rapport into the interview, the semi-structured protocol allows for participants' words and meanings to remain intact when (re-) presented in the research.

During interviews, the researcher collected background information and sought answers to questions about opportunities, constraints, and impact of the reflective teaching journal. In addition, the researcher sought information about experiences in CFGs and in the field/practicum component of the course.

Along with collecting artifacts, the researcher maintained a researcher's log throughout the project, making weekly entries into the $\log$ throughout the semester, documenting observations related to the CFGs (in-class meetings and online discussions). In pre-interview entries, the researcher made notes grounded in observations of the participant in class and in relation to observations of them in their field placement. In post-interview entries, the researcher documented personal interpretations of the interview along with questions and insights to pursue.
The process of data collection and analysis was ongoing, dynamic, and recursive (Merriam, 2007). Deductively, the researcher began the analysis by situating participants' notions and understandings of reflective teaching practice in relation to levels and traditions of reflective practice uncovered in the reviewed literature (Dewey, 1933; Liu, 20 I5; Schön, 1983;Van Manen, 1977; Zeichner \& Liston, 2013). Specifically, the researcher read through the reflective teaching entries submitted by participants (a total of 4 entries) and coded entries accounting for levels and traditions of reflective practice (e.g., technical, practical, critical, conservative, social justice). As well, the researcher sorted out the initial and "final" definitions of individual participants and noted excerpts illustrative of the predetermined categories (e.g., reflection-on-action/technical competence; reflection-in-action/critical reflection) and made observations related to whole group and by content-area. Additionally, the researcher used deductive methods of reasoning to situate data in relation to reviewed literature and personal experiences, reading the data against a backdrop of professional literature on dimensions of reflective practice, predictable developmental stages experienced by beginning teachers, and the stability and inflexibility of beginning teachers' prior beliefs, images, and models of teaching and learning (Britzman, 2003; Bullough \& Stokes, 1994; Bullough, Knowles, \& Crow, 1991; Calderhead, 1992; Calderhead \& Robson, 1991; Griffith \& Tann, 1992; Knowles, 1992; Lakoff \& Johnson, 1980/2003; Lortie, 1975/2002). Further, the researcher reread data against a backdrop of personal experiences as a supervisor of TCs and student teachers and as a classroom teacher. These dimensions of personal experience played a factor in the researcher's reading of data.After rereading data through these lenses, the researcher constructed and shaped individual participant accounts of evolving understandings of reflective practice and the impact of a CFG on developing reflective practice.

Inductively, the researcher gave shape to the narratives analyzed here by crafting an "interim text" (Clandinin \& Connelly, 2000) or participant profile (Seidman, 2006) for each participant. The purpose of the profile/interim text was to "story" the participant's backgrounds and experiences throughout the field experience. The interim text was under continual revision as the researcher searched for patterns and themes across assignments 
and interviews, and pursued individual story lines. The researcher sifted through interview material and analyzed documents, keeping intact the words of participants while also adding details and insights to provide context and transition (Marshall, 198I). Initial themes provided shape for individual interim texts, including: "technical reflection," "self-criticism", "criticism of mentor teacher”, “student-centered,” “content-focused,” “practice-focused,” "contextual factors," "audience for reflection"). Rather than a linear, chronological, or "finalized" account, the interim text is an ongoing, evolving, and unfinished transformation of a variety of genres into a story (Mishler, 1986; 1999).

After creating "interim" texts, the researcher continued the process of analytic induction, identifying themes and patterns across the data and generating initial claims within each case. Next, the researcher revisited the data, coding instances illustrative of particular themes (e.g., reflective practices; self-criticism; outward criticism). Through the ongoing comparative process, the researcher continued to refine themes and categories, adding, collapsing, and dropping as needed. As the researcher "storied" data to form narrative case studies, the researcher sifted through strands connecting themes and gleaned insights into shifts in individual understandings over time. Finally, the researcher looked across case studies to search for patterns providing insight into changes that occurred.

\section{THE CASE STUDIES}

Rather than an account of all 9 participants' perspectives, this paper focuses on the in-depth accounts of three participants. On one hand, presenting only three perspectives serves to limit the perspectives represented in the data. On the other, an examination of a small number of participants provides for more intensive and comprehensive accounts of individual experiences. Rather than present disconnected and decontextualized voices, it is the researcher's intention to provide additional context to allow for a more complex and deeper understanding of the individual case.

\section{Rose, ELA}

Rose (2I) was a secondary English Education major. Her placement for the fall 2017 semester was in an $8^{\text {th }}$ grade English Language Arts classroom in a predominantly white, middle class suburb located outside of River City.

\section{How did Rose view reflective practice?}

At the beginning of the semester, Rose defined reflection as a process by which teachers account for what is working, what is not working, and why. Rose's definition of a reflective teacher was not dramatically transformed throughout the semester, however, in her semester reflection, she did elaborate on adding to her definition the importance of seeking feedback from students:

I originally wrote that I think [reflection] means acknowledging what is and what isn't working in the class and why. I would add to it now saying that it also means seeking feedback from not your colleagues (even though that can be helpful), but your students.

While her original definition still served to be essential to her definition of reflective teaching, a key area for her growth involves her insight that reflective practice is more than a soli- tary activity of an individual teacher. At the end of the semester, she viewed reflective practice as more of a collaborative than a strictly individual process. Rose now viewed a critically reflective teacher as one who also sought feedback from their students, evidenced in her concluding sentence to the above excerpt from her semester reflection: "[The students] are the ones who are going to be the first to tell you what's working and what's not."

Rose found value in the requirement to maintain a reflective teaching journal to submit for course purposes. For instance, in her semester reflection, she writes,

Reflective teaching has been extremely helpful throughout this semester, especially as a new teacher. Taking notes and writing about problems, questions, issues, and the good things too has helped me make connections between class content and my field experience. The general process of writing is beneficial for getting one's thoughts organized and working through thoughts on your own while they are happening, instead of having to wait until class time that week to discuss.

At the same time that she found value in maintaining the journal, she experienced the instructor-outlined format for the assignment to be cumbersome. While other participants indicated they found the guiding questions helpful to refer to when writing the course-required reflective teaching entries, Rose felt confined by the "summary and response" expectations for the reflective teaching entries. She indicated that she would have preferred more of a "free write" reflection, assigned to "simply write out a page or two about whatever comes to mind" rather than follow a structure. In initial reflective teaching entries, Rose was often focused on her involvement and/or lack of involvement with her students.As she listened to her peers describe their experiences in their field and compared her experience, she felt that she was not provided with similar opportunities in her placement. Over time, the focal point of Rose's analysis moved from a mostly inward focus on worries and anxieties to include an analysis of the outside forces impacting the conditions of teaching and learning in the early $2 I^{\text {st }}$ century. Importantly, the reflective teaching journal provided Rose with opportunities to put herself in position to confront real issues faced by teachers in schools.

Rose had opportunities throughout the semester to engage in important conversations with her mentor teacher. One topic of conversation that proved instructive throughout the semester related to the topic of the middle school students and gender identity. In a reflective teaching entry, Rose summarized a dilemma that she and her mentor teacher were facing.

There have been two instances where [my mentor teacher] has been approached by students who identify as a different gender. However, the one student is supported by their parents, and the other is not. The student wants to identify differently but is afraid by doing so their teachers will mess up and use the wrong [preferred gender pronouns]/name with that student's parents. My cooperating teacher is having a tough time dealing with the issue.

In Rose's written response to the interview questions, she explained that this situation was an impactful experience for her to reflect on throughout the semester. In describing why this situation was "critical" to her, she writes,

My mentor teacher informed me of the situation one of the first days of field, and she confided in me her own confusion 
of how to handle the situation. She, at first, was avoiding addressing the student by any name at all, but eventually it was inevitable, and she had to ask the student again what name they wanted to go by. ... it was definitely a unique circumstance that I did not think I would have to face in my first field experience.

It is important to point out here the power and privilege wielded by both Rose and her mentor teacher in terms of their "common sense" expectation that they are/would be exempt from engaging in consequential social and political identities/issues/ topics in the classroom by virtue of their status as a beginning or experienced teacher.

In terms of supporting students and gender fluidity in the classroom, Rose made note in her reflective teaching journal that she is not simply practicing to be a teacher in the future, she is acting as a teacher in the present. From her reflective teaching journal:

While I look to [my mentor teacher] to see how she is going to handle the situation [of fluid gender identities in the classroom] as a role model for how I can handle future situations like this myself, it is also a question of, "How I am going to handle the situation?" too. This student is a member of my classroom, and I do not want to avoid the situation.

At one time, Rose conceived of her role in this middle school field experience perhaps primarily as a detached observer, occasionally taking notes for future teaching. However, future teaching, Rose discerned, comes out of the present, and in the present, there are no circumstances for detachment and/or inaction.

\section{How did Rose view the CFG?}

Rose was not particularly impressed with her overall experience in the CFG. In her experience, other group members dominated the group's attention, so she rarely had time to share and receive feedback. At semester's end, she wrote,

I liked the idea of the critical friends group because it was nice to just discuss, but I also didn't find it very beneficial. I liked to read about other people's experiences and concerns, but I don't think I ever received feedback on mine.

Further, while she enjoyed reading about the experiences of her group mates through their posted reflections on the course's online platform, she received very little, if any feedback, from her group members, on her submissions. Rose continued:

It was hard to discuss our experiences because each of us came from different content areas and didn't really have much to say on how to help each other out. Some people, specifically, in my group only talked about themselves. I very much enjoyed getting in my job alike groups because they would be able to make more useful suggestions to me.

Overall, Rose seemed mostly indifferent toward her experience in the CFG, writing, "I learned about issues that go on in other content areas, but like I said it was hard to help each other." While several participants found it beneficial to work in content-diverse friends groups to discuss "puzzles of practice" (e.g., Ericka, Ellen, \& Megan), Rose felt that it was "hard to help each other out." In addition to perhaps feeling inadequate to offer advice in a content area that was not her expertise, Rose described feeling constrained by the time allotted to the group each week in class, writing,"I felt that I had to keep it short because of time and therefore everyone else was eager to talk about their own experiences." Rose indicated her content-alike group was more useful in supporting her than others. In this "job-alike" group, she felt more of a shared commitment to and perhaps better equipped to provide and receive support from a group consisting of five other prospective secondary ELA teachers.

\section{Megan, Science}

Megan (2I) was placed in a $7^{\text {th }}$ grade science classroom in a predominantly white, rural middle school.

\section{How did Megan view Reflective Practice?}

At the beginning of the semester, Megan (2I) wrote that critically reflective teachers are "[c]ritical of themselves - teaching style, student engagement, classroom management." In addition, she described critically reflective teachers as "[c]ritical of expectations - fulfilling demands, incorporating other important topics, challenging school requirements." Lastly, Megan listed that reflective teachers were critical of peers by "challenging other teachers to be better [and] building community and relationships." Megan did not provide a context for her definition of critical, though it appears that "being a skeptic" or "inclined to criticize" feature prominently in her initial definition over other dimensions of the multi-dimensional term critical (e.g., fault-finder; being negative; incisive; bringing into focus oppression, supremacy, bias, racism, sexism). This early definition of critical reflection took into account multiple dimensions of reflection, including both inward and outward shifting and processing that move one beyond reflection on mere technique.

In the interview, Megan described growth in thinking about reflection. Seeking formative feedback from colleagues and students became more fundamental to her definition. "Now that I understand [reflective teaching] a little bit more," she began,

[l] t's not just an individual process of looking back at what l've done and how it worked. It's also a social process. So, getting feedback from students as well as peers and other faculty members. I think that is also a very important part of reflection. And I think it's an ongoing process. It never really ends.

Similar to Rose, her perspective on reflective teaching at the end of the semester took into account reflection as a (social) process rather than a single-occasion individual accomplishment. While the researcher did not probe the source for Megan's newfound ideas about reflective practice - for instance, did she attribute her change in views to her CFG experience or to other factors related to her field experience (e.g., her mentor teacher, $7^{\text {th }}$ grade PLC team at site) - the growth is likely attributed to a combination of experiences.

Another key change in Megan's definition of reflection related to the form of it. Megan now viewed reflection as more dynamic than just the written word:

One thing I have learned about how to reflect is that it doesn't take on just one form. It can be a mental process, written process, or verbal where you talk to peers. Throughout the semester, I often spoke to my mentor teacher after lessons to ask what, if anything, would be changed for the next class period. If I noticed students were not engaged or distractions arose or confusion was evident, we worked together to figure out how to change the lesson to be more 
effective. During class was another format for reflection, speaking with peers going through some of the same things as me.

Prior to participation in this inquiry project, Megan conceptualized reflective practice more as a written product than an internal or external dialogue with the self or others. In an important contribution to the study of reflective practice, Schön (1983) explained that reflection can be viewed in two time frames. The first frame, reflection-on-action is conceived as reflection that occurs before and after an action. For teachers, reflection-on-action occurs prior to the implementation of a lesson, during the planning stages of a lesson, as well as after the implementation of a lesson, when teachers consider the effectiveness of their instruction on student learning. Not too surprisingly, prior to her initial field experience, Megan's conceptions of reflective practice weighted heavy the reflection-on-action frame. The second frame, reflection-in-action, however, occurs during the action of teaching, when teachers find themselves making adjustments to their planned teaching because of an unexpected student (mis) perception. While teachers frequently solve classroom problems on the spot without consultation of others, reflection-in-action can also occur as teachers have reflective conversations with one another about their practices and problems. Reflective practitioners, according to Schön, are reflective both "on" and "in" action. In Schön's terms, then, Megan once weighted heavy in her definition of reflection the practice of reflection-on-action; by the end of this inquiry, however, she gained valuable experiences related to reflection-in-action.

In her first reflective teaching entry of the term, Megan used her reflective teaching journal to analyze a bullying incident involving a group of middle school students. A group of male adolescents were taunting and bullying another young male because of his "really longer hair." Rather than standing by as a silent witness, Megan writes, "I intervened," continuing:

I did not want this young boy to be so ashamed of something as arbitrary as the length of his hair, that he would [resort] to cutting it. It would be devastating to see such a statement of individuality ... dissipate because of the taunts of some middle school boys.

She next described her intervention in the situation by discussing, with the boys, examples of "men at the height of 'masculinity' who also had long hair." In the discussion, she drew upon her knowledge of students' admiration of several professional athletes currently enjoying public celebrity.

Casting an eye toward the future on how the situation described may impact future practice, Megan articulated goals related to interrupting systems of patriarchy and white supremacy, writing:

I don't want my [future] classroom filled with just the stories of old white guys. I want diversity of beliefs, values, skin color, gender, orientation, sex, ideologies, and even hair length to be included as examples to my students. It is important to see that people like them can be successful and no arbitrary aspect of their physical appearance should act as an obstacle to that success.

Rather than locating the bullying as rooted strictly within the individuals involved, Megan considered how systems of power (e.g., patriarchy, culture of masculinity) play a significant role in defining acceptable or "official" knowledges, behaviors (e.g., dress, hair, gestures), and attitudes (Apple, 20l4).

Megan frequently used the reflective teaching journal as a place to make plans to disrupt familiar routines in her future teaching. In one example, Megan connected sexism in the adult world to examples of sexism in schools and classrooms today. In her words,

Gender biases still exist in the classroom ... boys are called on more often, are given more direct instruction, are allowed to explain their answers more fully, and are given over all more attention from the teacher ... Boys are also believed to be better at math and science, while girls are believed to be better at reading. Because of this, there is a huge shortage of women going into STEM fields, especially engineering .... It is our duty as teachers to recognize gender bias in our classrooms and make a point to reduce their effects.

In this passage, Megan gave thought to the role of gender inequities that exist in education, including beliefs about innate abilities in the sciences and mathematics. In addition to demonstrating awareness of the inequities, she considered it part of her duty to disrupt these powerful myths by challenging the discourses, norms, and assumptions often at work in schools.

In her final reflection, Megan grounded her notion of a critically reflective teacher as someone who challenged traditional expectations of teachers, including following a curriculum aligned (or not) to particular standards. "Keeping up with the standards is very important," Megan writes, "but I want to teach more than just to the test." Megan was not naïve in her understanding of the challenges that await before her as someone who strives to be a critically reflective teacher, writing further on in her semester reflection, "Challenging school requirements and fulfilling the demands of the school district is also part of being reflective. ... [but I realize] it is difficult to bring new practices into a district if the school is not open to change."

\section{How did Megan view the CFG?}

While Megan found value in consistent in-class debriefing with her CFG, she experienced what she described as "pushback" on her ideas, which led to her overall disappointment of the CFG experiment. In the interview, she stated, "I found it somewhat difficult to voice my own views or ideas or thoughts about a topic. Sometimes I felt like I got quite a bit of pushback on some of my ideas." Megan explained that she was not the type of person who felt challenged by others' ideas, rather, she "just didn't think there was enough dialogue going on [in the CFG] to really make those differences in ideas really beneficial." In addition to the perceived pushback, Megan revealed her CFG colleagues did not provide her with consistent feedback on her reflective teaching entry submissions throughout the semester. As outlined in the syllabus, Megan should have received some brief electronic feedback from a group member on at least three occasions during the term. However, in practice, she could only recall one occasion whereby she received a note on her entry. In the interview, Megan elaborated:

So that was kind of a disappointment to me because ... everybody only responded to one [group member's reflective teaching entry], but multiple people responded to the same 
one. So, I found that a little bit disappointing that I wasn't receiving that feedback.

Megan questioned whether her group members actually read her reflective teaching entries, and expressed disappointment when it came to posting her reflective teaching entry on an electronic-group platform, only to receive little to no feedback in return.

\section{Ericka, Spanish}

Ericka (2I) did her initial practicum in a middle school Spanish classroom in a suburban setting.

\section{How did Ericka view Reflective Practice?}

Ericka initially defined a critically reflective teacher as someone who questioned their work and sought continuous improvement. In her early definition of critical reflection, she wrote:

Being a critically reflective teacher means continuously questioning your work. What went well? What didn't? How does the group demographic change that? Always looking for new ways to improve your teaching using the information you found from past experiences. Questioning your work isn't a sign of weakness/self-doubt and critically reflective teachers recognize that to continuously improve their work.

Her definition remained fairly static over the course of the semester, although she indicated she began to see reflective practice as allowing for formal and informal channels of expression, and that it was important to participate in both of these means of expression. In the interview, she further explained,

Because you can informally reflect on everything you are doing in the classroom. But if you don't take the time to sit down and really think, here's what l'm doing, here's what they are doing, here are the discrepancies, then, what does that say about the system? Nothing is going to change.

In practice, Ericka tended to look beyond individual student misbehaviors, and chose instead to examine systems of power at work in the classroom and school building.

Near the end of her placement in a suburban middle school Spanish classroom, Ericka's mentor teacher took an extended leave. Ericka ensured a smooth transition for the long-term substitute, who relied on Ericka's knowledge of students and routines. While all of TCs were encouraged to submit "non-traditional" reflective teaching entries, Ericka was one of two teacher candidates (out of 29) to experiment with format. In addition, she was the only TC to submit two "non-traditional" reflective teaching entries. In her first reflective teaching entry of the semester, Ericka uploaded a concept map depicting the three main areas required for the reflection: summary, analysis, and health \& wellness (see Fig. I).

The purple on the concept map represents Ericka's "analysis" section of her reflection. The central "nerve" in the analysis reads: "Social Justice Teaching: Student making racist comments in class (multiple occurrences)." Four "branches" surround this block of text, respectively titled: "subtle inequities"; "overt inequities"; "hears comments from parents/tv"; and "restorative justice." The "restorative justice" node splits into seven interconnected branches, including: (a) Took kid on a walk after a specific comment was made, (b) Focused on why that would offend people of color, and (c) Made plans to change behavior in future.
Surrounding the "subtle inequities" text box, Ericka placed seven junctions, including (a) Co-op teacher does not address them in front of class (if at all), (b) Shows students of color their identity being disrespected is less important than teaching, and (c) Other kids know he did something wrong, but don't understand the "why." In the interview, Ericka provided additional context about this event:

[The student] was having a conversation with some kids. And I was standing near them. And he said something about bringing back the Fourth Reich. And immediately I told him that it was not appropriate. But it was my first week there, it might have been my first day, actually, in the classroom, and I didn't know where my line was in terms of talking to students and disciplining students like that. So I told him immediately it wasn't appropriate, I didn't want to hear it again, and then I went to go talk to the cooperating teacher. Because, it's her classroom. And I didn't know where my boundaries were, so I was hoping that she would address it, but she did not, so ... That [event] has still bothered me. And not so much that he made [the inappropriate comment], because I know he's just repeating whatever he's heard from a parent, or a tv show. I know those aren't his own thoughts. But, when that wasn't addressed, it kind of clicked in me that that happens way too frequently, where kids make comments like that, and they are not addressed. They are swept under the rug. Or maybe they are addressed, but they are addressed haphazardly, and not to the fullest extent in which they should be. And, that's how we perpetuate systemic racism. So, that one [event] has hung on for a while.

Beginning with the initial reflective teaching entry, Ericka's exploration of how "invisible structures" in society map onto the schooling experience was on display.

In her second reflective teaching entry, Ericka submitted a three-column poster outlining her personal and professional updates (see Figure 2). In this entry, through self-initiated informal data collection, Ericka made the observation that Hispanic students were not being called on as often as their White peers. She wondered if this might lead to Hispanic students "not feel[ing] their voice is as valued." Further, she expressed concern about the loss of in-class practice and the dysconscious (King, 1991) assumptions being made about the students.

In a mid-term reflection assignment, Ericka confronted a dilemma she was experiencing as she code-switched, or switched between colloquial and formal/academic variations of English, in interactions with students:

During student work time, I walk around the classroom and interact more heavily with the students and their assignments - asking questions, clarifying information and directions, and connecting with the students. I also wonder if my communication style with the students is more lax than it should be. I sometimes talk to them in a more colloquial fashion, but it seems to get a better response out of them than it would if I were to make my speech more professional. I have been able to connect with students that may not have bothered to know my name because of that. I have been working on code switching, or switching varieties of conversation, in order to connect with both my students and colleagues. However, I am not sure if it is considered unprofessional or not - something I should ask my mentor teacher. 


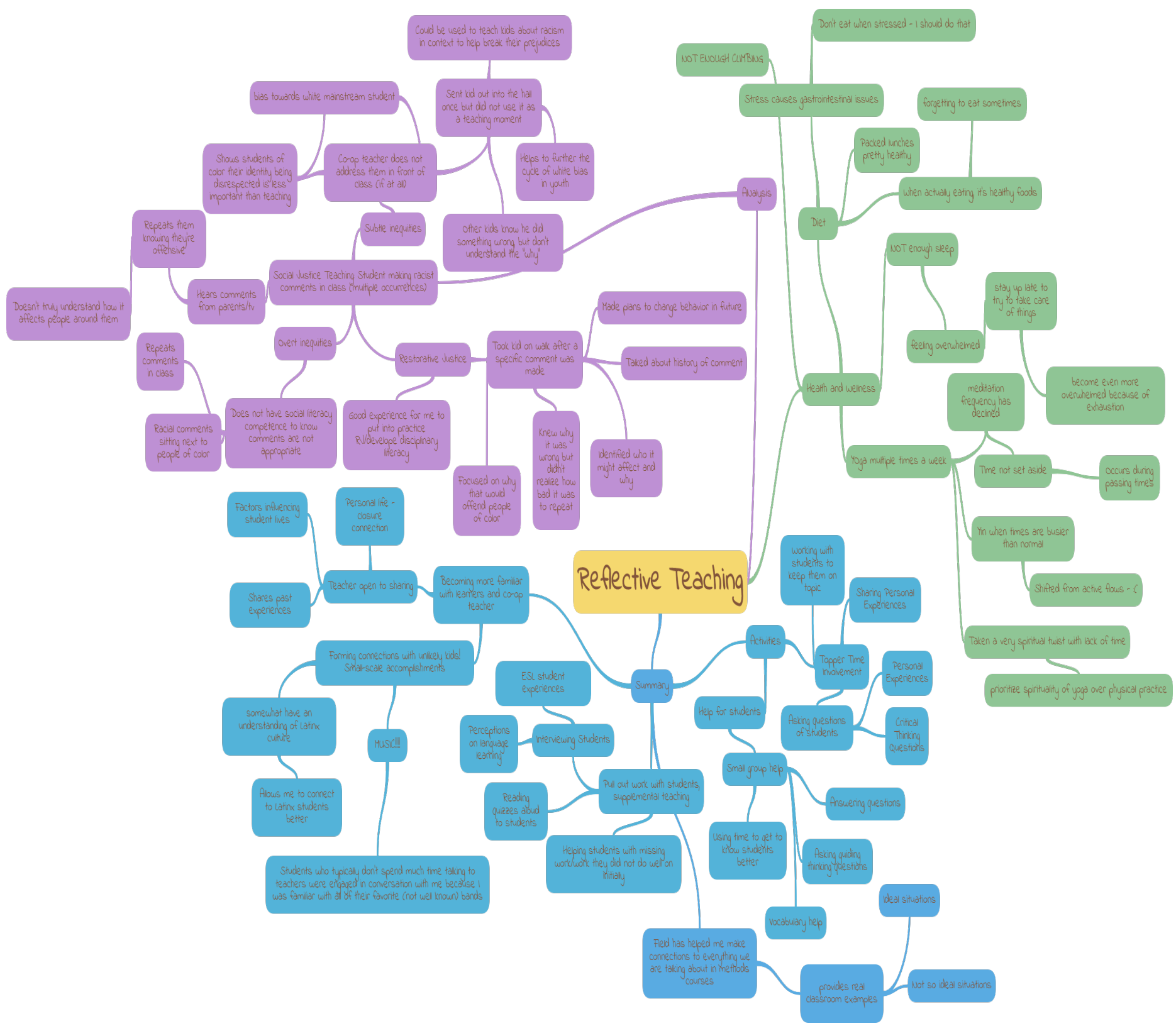

Figure I. Ericka's Initial Reflective Teaching Entry

Here, we see Ericka confront a dilemma related to language use. Delpit (1993) has written extensively about the dilemma faced by (white) teachers as they try to recognize home/school mismatches experienced by their culturally and linguistically diverse students. We also see how written reflection, for Ericka, served as a vehicle for encouraging herself to engage in a future conversation with her mentor teacher about the relevance and/or importance of code-switching when interacting with students.

Overall, Ericka's reflective teaching entries demonstrated several key aspects associated with critical reflection, including focusing on social and political issues, raising questions, interrogating assumptions, and being vulnerable.

\section{How did Ericka view the CFG?}

While Ericka focused on structural aspects of schooling and socialization in her written reflections, she recognized her CFG conversations and reflections were focused more on individual student behaviors than on structural or systemic aspects of schooling. Reflecting on her peers' entries, during the interview she shared,

I think a lot of [my peers'] reflective teaching entries focused on student behavior a lot. And not necessarily student behavior that leads to the perpetuation of systemic racism, but like student behavior like kids being 'bad.' And that bothered me. I feel like it was a reflection, but it wasn't a high enough level of reflection. So that bothered me a tad.

Ericka tried to interrupt some of the perceived low-level reflection by asking questions (e.g., "Why do you think this is going on?") but she did not see the interruptions as having much of an impact. Although Ericka perceived herself to have become more reflective during the semester, she did not see the CFG as the 


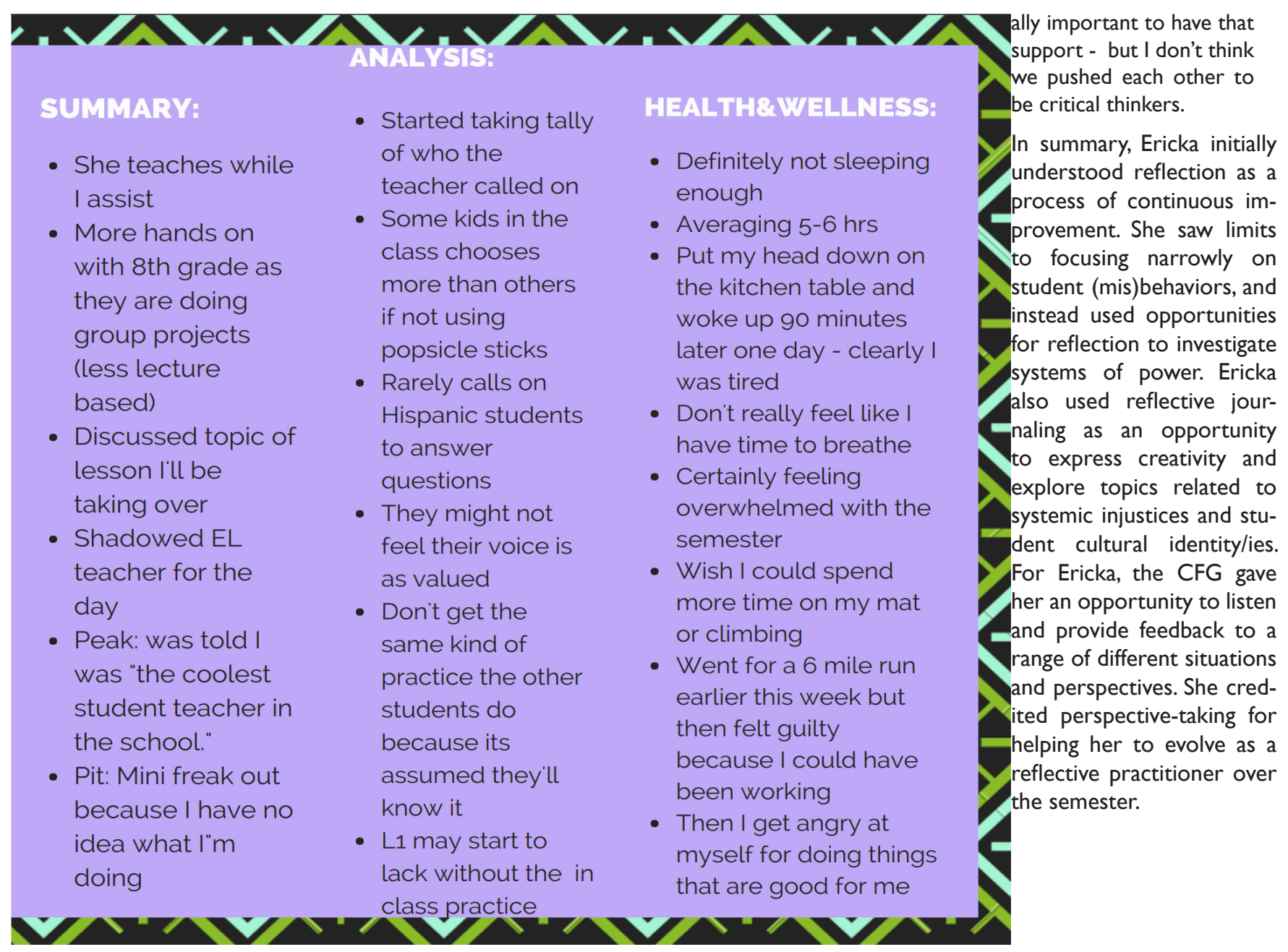

Figure 2. Ericka's Reflective Teaching Entry 2

contributing factor to her growth or as a universal remedy for critical thinking.

Ericka actively resisted the impulse to reflect on student (mis)behaviors, stating that a narrow focus on the individual ignores (and sanctions) underlying systemic issues. In her words,

I focused more on invisible structures in schools. Because, when it comes to student behavior, I think a lot of that is reflective of the school experience that they've been having. So, maybe it's naïve of me to say so, but I don't think there are bad kids. I think there are bad circumstances. I try not to focus on student behavior, because it just didn't seem like something easily changed. I feel like in order to change student behavior, you have to change the system in which they are learning. So I focused more on that system and the underlying social justice issues that aren't being addressed ... throughout the semester. I didn't sway from that much ...

Ericka was resolute in her efforts to promote social justice efforts across schools and classrooms, including in her final presentation on English Learner rights and school's responsibilities. Despite her efforts to be an advocate for social justice, she did not experience her CFG as a space for critical thinking, per se. According to Ericka, when it came to the CFG,

The emphasis was a friend group. I don't think we really pushed ourselves to like - I think we were there to support one another, very much so, I think it was really, re-

\section{DISCUSSION AND IMPLICATIONS}

The individual storylines provide direction for answering this study's outlined questions about beginning TCs' understandings and practices related to critical reflection. Individually, it is possible to see characteristics of reflective teaching observed in the literature (e.g., technical, practical, critical reflection). In addition, each participant provides insight into the role of a CFG in supporting (or not) beginning TCs as they practice reflective teaching. The perceived importance of the CFG, or each individual's overall rating of the CFG, varied on a case-by-case basis. Ericka experienced the group as friendly, but mostly uncritical. Rose and Megan were mostly indifferent to the CFG arrangement; the group did not live up to its billing as an open and supportive network of friends for them.

A look across individual cases provides opportunities for examining broader implications of this investigation into beginning teacher candidates, notions of reflective practice, and critical friend groups. Three broad lessons learned and reinforced through this investigation into the local will be elaborated on below:

I. Critical reflection can and does occur in beginning TCs' practice (when it does occur, is not always the result or effect of a CFG), 
2. CFGs led to informative learning, but not transformative learning,

3. Designating a group "critical friends" is neither a guarantee of critical thinking or friendship

Critical reflection can and does occur in beginning TCs' practice (when it occurs, it is not always the result or effect of a CFG)

During the first week of her placement in an 8th grade ELA classroom, Rose was confronted with teaching and learning dilemmas she had not anticipated for her initial field experience. Two middle school students at her placement did not fit neatly into the gender binary. The students' identities presented Rose (and her mentor teacher) with opportunities to consider how to support a range of expressions of gender in the classroom and throughout the school and community. Rose embraced the dilemma as a learning opportunity to practice in the present what she aims to practice in the future in terms of supporting all of her students, regardless of their diversities (race, social class, gender expression, sexual orientation, ability/ies).

After observing a small group of students bullying an individual student, Megan used her reflective teaching journal to consider the incident as yet another instance which occurs with persistent frequency within the systems of patriarchy and masculinity. Ericka's initial definition of critical reflection tended to emphasize a cycle of continuous improvement based in part on a willingness to self-criticize. In practice, Ericka consistently demonstrated key aspects of critical reflection related to disrupting familiar routines (e.g., submitting "non-traditional" reflective teaching entries; seeking to disrupt "silent" or passive acceptance of racist/sexist viewpoints), focusing on social and political issues, and raising questions (Lewison, Flint, \& Van Sluys, 2002).

While evidence of critical reflection was observed in assignments, written reflections, and interviews, less evident in this study is any direct correlation between critical reflection and CFGs. Rose, Megan, and Ericka all demonstrated capacities for critical reflection; at the same time, none of them attributed their experience in a CFG as a contributing factor to their capacity for critical reflection.

Teacher educators seeking to develop critically reflective practice in TCs admittedly face a number of barriers related to such a task (Boud \& Walker, 1998; Flessner, 2014). In addition to challenges of context (Boud \& Walker, 1998), the conventional understandings of a teacher's work certainly stand in the way. In general, reflection is not associated with the working life of a teacher (Hatton \& Smith, 1995, p. 36). According to this domineering conception of the profession, teaching is construed as dealing with the immediate present through pragmatic action, while the act of reflection is viewed as a pursuit of university academics. Teachers, already tasked with unreasonable expectations and requirements, simply do not have the time (or the luxury) to reflect on their teaching and/or their students' learning (Flessner, 2012; Hatton \& Smith, 1995).

Additionally, attention to reflective teaching, it is argued, further intensifies the work of teachers, and in this case, the workload of cooperating teachers. While proponents of teacher reflection make the case that reflective practice is a liberating and/ or emancipating practice (Calderhead, 1989; Dana \& Yendol-Hoppey, 2008; Burke, Marx, \& Berry, 200I I), teacher reflection also might be conceived as a tool to subtly control teachers (Fendler, 2003; Zeichner, 2008). This is particularly the case when teachers are asked to conform to a program or scripted curriculum. In the case of assigning TCs to reflect on their teaching/classroom, questions emerge about motivations for reflecting in an honest way, as opposed to reflecting in a way that will be viewed as acceptable by the supervisor and/or cooperating teacher (Valli, 1992).

In addition to the above barriers, the question of whether or not preservice teachers are developmentally ready for the task of critical reflection has been up for debate in the research on teacher reflection (Kagan, 1992; Valli, 1992; Zeichner, 2008). Skeptics of critical reflection argue that teaching is a technical activity, therefore, TCs should be directed to focus on the means and ends, rather than on the moral, ethical, and sociopolitical dimensions of teaching (Law, 2005). Some argue that efforts to engage preservice teachers in critical reflection are premature, misguided, and political indoctrination (Gore \& Zeichner, 1991; Valli, 1992). However, as Valli (1993) states, "capacity for reflection is not merely a function of age, but a function of both age and educational experience ..." (p. 40). The researcher's observations and analyses provide evidence that TCs have the capacity to move beyond technical and practical levels of reflection. Further, in many instances, TCs strive toward critical reflection without needing instructor encouragement.

Valli (1993) contends TCs can develop the capacity for critical reflection, particularly if they are taught reflection as a holistic construct, rather than an ordered set of discrete skills. Routines and strategies for teacher educators to implement, include modeling reflection, providing guided practice in reflective thinking, creating a system built around clinical practice, revamping curricula, reconnecting with classroom practice, and conducting practitioner inquiry (Flessner, 2012; National Council for the Accreditation of Teacher Education, 2010; Valli, 1993). Moving forward, instructor modeling and guiding of reflective thinking hold tremendous potential for future practice (Lee, 2005; Valli, 1993). Further, there is a growing body of research on the use of protocols in supporting teachers as they transform practice (Fahey \& Ippolito, 20I4; Ippolito \& Pomerantz, 20I4; Norman, Goaian, \& Hooker, 2005). Emphasizing and modeling a range of pedagogical strategies, particularly those beyond writing, including oral/verbal and audio/visual/digital reflection holds potential for reflective teaching to flourish (Foster, 2015; Jones \& Ryan, 2014; Lee, 2005; Sturgill \& Motley, 20I4).

At the same time educators must take steps to nurture critical reflection, it is important to recognize a number of cultural and institutional impediments to fostering critical reflection in TCs, including the high-stakes, summative assessment known as the Teacher Performance Assessment or edTPA. At RCU, TCs must pass the state's cut score on the edTPA during their student teaching experience in order to be granted licensure. As Liu (2015) has argued, the high-stakes nature of the edTPA (a distant, anonymous assessor with no knowledge of the context or the candidate), actually encourages tactics that stand in the way of reflection, in particular, "sun shining and cherry picking" (p. 153). While high-stakes tests pressure TCs to put their best foot forward, it is important to acknowledge that teacher educators are not immune to the pressures to "teach to the test." As programs and teacher educators feel pressure for their TCs to pass the arduous test, concerns about rankings based on edTPA 
performance soon outweigh any efforts to encourage, promote, and support critical reflection.

\section{CFGs led to informative learning, but not transformative learning}

The interdisciplinary CFG Rose spent time in neither contributed to nor necessarily fostered critical reflection from Rose. While she described in her reflective journal some of the dilemmas she encountered related to students' identities, she did not receive online feedback on the dilemmas from her group members. In class, others who were "eager to talk about their experiences," seemed to overshadow her (limited) contributions to the group. Constraints related to the limited time each group member had to share in class and her nascent relationship(s) with members of this interdisciplinary group appeared to factor in to her overall CFG experience. Overall, Rose described her content-alike/job-alike group as more beneficial than her CFG.

Similarly, Megan did not feel particularly supported in her CFG. Yet, this did not seem to stifle her willingness to engage, on an individual level, in critical reflection. In addition to experiencing "pushback" on her ideas in face-to-face settings, Megan was disappointed at the lack of feedback she received from her group mates in the online forum for the group. While she valued having a consistent group to converse with, the group by no means supported her efforts to "try on" a critically reflective stance. Of course, factors related to age, gender, beliefs about the purpose of education, ideological stances, composite of the group in terms of content areas, and even the value placed on the group likely play a complex role in understanding the outcome of this particular CFG. Despite these circumstances, Megan prioritized the act of critical reflection in her reflective teaching entries, exploring issues and questions of power, patriarchy, and masculinity in schools and schooling. That is, despite a CFG that remained mostly indifferent to the purpose/aims of the group, Megan sought to be critically reflective by raising and pursuing important questions about power and education and by disrupting familiar routines related to the role of gender in careers in science and/or mathematics.

Ericka explained that the emphasis in her CFG was on the "F"' as in friends, more so than on the "C" for critical. The dynamic of friendship, then, appeared to be more pronounced for Ericka, particularly in comparison to the experiences described by Rose and Megan. Despite having the ingredient of friendship, Ericka considered the content of her group's reflective entries and discussion to fall short of critical reflection. Whereas Ericka actively worked to put a spotlight on systemic or structural aspects of schooling (e.g., racism, sexism, linguicism), within her group she experienced a general avoidance of/silence on similar or related observations.

Drawing on the work of transformational learning theorist Mezirow (2000), Fahey \& Ippolito (2014) distinguish between concepts of informative learning and transformative learning. Accordingly, all learning experiences occur somewhere along the continuum between informative and transformative. Whereas informative learning is a kind of learning that increases what we know, it does not increase how we understand who we are or our world. In other words, transformational learning not only changes what we know, it also changes who we are and how we know what we know. The CFGs in this study seemed to result in informational learning (participants learned skills) more readily than transformational learning (participants learned more about who they are and how they make meaning of the world).

The research in transformational learning theory suggests that reflective discourse is "the engine that propels transformational (as opposed to informational) learning” (Fahey \& Ippolito, 20I4, p. I2). That is, transformative learning entails participating in collaborative conversation with others, learning from others' experiences and evaluations, examining assumptions, and taking action based on new insights (Mezirow, 2000, p. 8). Others make the case for the importance of constructive dialogue with others as central to transformative learning, including Breidenstein, Fahey, Glickman, and Hensley (2012), who argue that educators "cannot improve their craft in isolation from others" (p. 3, in Fahey \& Ippolito 20I4, p. 2). In addition to observing the practice of other teachers, feedback from colleagues and even one's students, it is argued, are necessary ingredients for improved practice.

Indeed, recent reform efforts aimed at transforming the professional development of teachers have resulted in the formation of Professional Learning Communities (PLCs) and even Critical Friends Groups (CFGs) (Burke, Marx, \& Berry, 201 I; DuFour, 2007). In part, such efforts serve to deprivatize the profession (Burke, Marx, \& Berry, 20II). In lieu of a "privatization of practice" model of teaching (privacy from scrutiny, some autonomy), Cochran-Smith (2012) argues for the deprivatization of practice or "the interruption of teaching as a private act" (Cochran-Smith, 20I2, p. II2). According to Cochran-Smith (20I2), "[ $t]$ he upside of deprivatization is the end of isolation" (p. II2). Instead of isolation, deprivatized practices offer collective construction of knowledge, collegial support and feedback, and collaborative communities working toward similar goals. At the same time, it is important to note that for some, deprivatization may increase anxiety and be experienced as threatening as it encourages teachers to admit uncertainties and to be vulnerable.

This shift toward deprivatization requires an interpersonal/professional view of teaching and learning, while teaching has traditionally been configured as an intrapersonal/individualized profession. In theory, this shift further positions teachers as subjects engaged in collective inquiry and action (strengthening the profession), rather than as objects of others' (e.g., organization's, educational expert's) development/reform agendas (Burke, Marx, \& Berry, 20II; Cochran-Smith, 20I2). In practice, however, tensions exist and are bound to surface as individuals are changing professional practices and whole-school reform is implemented via groups of individuals. While CFGs hold potential as a grouping mechanism for supporting reflective discourse that results in new practices, such groupings are by no means a universal remedy for institutional change or critical reflection.

\section{Designating a group "critical friends" is neither a guarantee of critical thinking or friendship}

Rose, Megan, and Ericka completed their practicum in different content areas (e.g., ELA, Science, \& Spanish) and grade levels (6th, 7th, \& 8th) during their initial practicum in the fall of 2017. While Rose and Ericka were placed in a suburban setting for their field experience, Megan was placed in a rural setting for the practicum. Each of them were placed in a small group $(n=4-5)$ comprised of a content-area diverse group of classmates, referred to as the Critical Friends Group or CFG. Rose felt more supported by and better equipped to provide feedback in her job/content-alike 
group than she did in her CFG. She seemed to view her ability to give and receive advice to come more easily in the job/content-alike setting. While having an interest and even an expertise in a particular content area certainly provides any professional relationship a head start, there is much to be said about the value of interdisciplinary teaching and learning (Shulman \& Shulman, 2004). Regardless, she did not attribute her participation in the CFG to result in or to revolve around critical thinking, neither did she attribute friendship as a result of the experience. In addition to not feeling particularly supported when sharing in-class, Rose did not receive online support from her classmates on her reflective teaching entries.

Megan could appreciate the time to process her field experience with her CFG, but overall, the experience was a disappointment for her. Similar to Rose, Megan did not receive any feedback from her CFG on her reflective teaching entries. In addition, in class, she described experiencing "pushback" from certain group members for expressing progressive ideas about education. For Megan, the CFG was mostly absent the friendship component. In parallel to Rose, she did not attribute her participation in the CFG to result in or to revolve around critical thinking. Further, she did not ascribe her critically reflective stance as the result of her work in her CFG. Like Rose, Megan received little, if any, feedback from her group on her reflective teaching entries.

Unlike Rose and Megan, Ericka did feel supported by her CFG.At the same time, she did not see the CFG as a contributing factor to her development as a critical thinker, nor did she view her group mates as being as motivated as she was to consider social and political issues and their impacts in the classroom. Whereas her group mates typically focused on individual acts of behavior (absent of social/political/cultural context), Ericka tried to connect individual actions to broader, systemic issues related to equity and justice. Overall, Rose, Megan, and Ericka share in common a general assessment of the CFG experiment, which is that calling a group "critical friends" does not guarantee critical thinking or friendship.

In an era in which instant communication is a part of everyday life, it can be challenging to sit back and wait for desired results. While CFGs hold potential as sites of/for transformation, criticality and friendship take more work than can be assigned/ accomplished during the course of one semester (Franzak, 2002; National School Reform Faculty, 2012). This iteration of CFGs, at the very least, provided TCs with opportunities to participate in collaborative dialogue. In this case, the CFG provided a structure for dialogue, including regular conversations about field experience with a small group of classmates from a range of content areas. In addition to the face-to-face sharing with group members, TCs shared reflective teaching entries electronically through an online learning management system and provided feedback to group members. As the instructor/researcher works to revise the CFG structure in future courses, revisiting the expectation that TCs read and electronically respond to a group member's teaching entry is necessary. As evident in the cases here, this key feedback loop process was not as productive or meaningful as intended.

In addition, if the requirement to respond to a peer remains, it is clear that guidelines and additional structures (e.g., examples of critical questions; sentence stems for asking for clarification/ evidence; rubrics for self/group assessment) should be developed. Along those same lines, feedback indicated that prompts for encouraging discussion on critical topics would be helpful for guiding future friend groups. This feedback aligns with Liu's (20I5) reminder that teacher educators cannot take for granted critical reflection capacities happen naturally, without support.

\section{CONCLUSION}

As noted by Tannebaum and Cridland-Hughes (20I5), students "listen" to what we do as teacher educators more than they "listen" to what we say (Avery, 2003). If goals for teacher education programs include developing critical reflection within its teaching ranks, routines and practices which promote such reflection must more consistently be modeled in foundational and methods courses taught by teacher educators.

The research presented here has demonstrated that beginning teacher candidates do have operational conceptions of a variety of aims for education as proposed by influential scholars in the fields of literacy and education. At the same time, their experiences in secondary and college classrooms as well as in their PDS sites for their field experiences often fortify traditional norms and behaviors surrounding notions of "the individual teacher working in isolation" from other adults (colleagues, administrators, parents, and other community partners and members). Such experiences serve to solidify status quo approaches to teaching, learning, and reflective practice. If goals for a teacher education program include promoting critical reflection, such goals must be explicit in program's conceptual framework(s). Additionally, teacher educators must introduce TCs to practices and protocols that support critically reflective thinking. Barton's (20I2) research suggests that preservice teachers do not arrive to their university studies with goals related to engaging in a democratic struggle for social justice. Instead, they consider teaching for reasons such as enjoyment in working with youth and seeking to be a role model. Around their junior year, however, many are ready to begin to internalize critical dispositions toward the purposes of education. Opportunities for increasing preservice teachers' confidence in being critically reflective exist through pedagogical supports such as the CFG. However, as the research findings presented here have demonstrated, a critically reflective outlook is not necessarily the result of or the effect of a CFG.

While the CFG is clearly not a panacea for critical reflection or critical friendship, experience holds potential as preparation for future critical reflection. Prospective teachers inevitably encounter the realities of schooling. When they do encounter such issues, they have limited choices: "to unquestionably accept current school practices, to leave the profession, to effect change in their own classroom only; or to dialogue with colleagues about important issues" (Valli, 1993, p. 42).Arguably, teachers who have critically reflective preparation are in a better position than those who have not been prepared to be critically reflective to choose the route of collaborative dialogue.

\section{ACKNOWLEDGEMENTS}

This research project received generous support from the office of the Provost of the University of Wisconsin - La Crosse and UW System's Office of Professional \& Instructional Development's (OPID). 


\section{REFERENCES}

Anney, V. N. (20I4). Ensuring the quality of the findings of qualitative research: Looking at trustworthiness criteria. Journal of Emerging Trends in Educational Research and Policy Studies, 5(2): 272-28I.

Anyon, J. (1980). Social class and the hidden curriculum of work. Journal of Education, I62(I), 67-92.

Apple, M.A. (20I4). Official knowledge: Democratic education in a conservative age ( $3^{\text {rd }}$ ed.). New York: Routledge.

Artiles, A. J., \& Bal,A. (2008). The next generation of disproportionality research:Toward a comparative model in the study of equity in ability differences. The Journal of Special Education, 42(I), 4- I4.

Avery, P. G. (2003). Civic education in the preparation of social studies teachers: Research-based recommendations for the improvement of teaching methods courses. Clearinghouse for Social Studies/Social Science Ed. In ERIC Digest: Clearinghouse for Social Studies/Social Science Ed. Bloomington, IN: ERIC.

Ayers,W. (1993). To teach:The journey of a teacher. New York: Teachers College Press.

Bambino, D. (2002). Redesigning professional development: Critical friends. Educational Leadership, 59(6), 25-27.

Barton, K. C. (20I2). Expanding preservice teachers images of self, students, and democracy. In D. Campbell, M. Levinson, F. Hess (Eds.), Making civics count: Citizenship education for a new generation (pp. I6I-182). Cambridge, MA: Harvard Education Press.

Beyerbach, B. (2010). Themes of sixty years in film: Fast times, dangerous minds, and stand on me. Educational Studies, 37(3), 267-285.

Boud, D., \& Walker, D. (1998). Promoting reflection in professional courses:The challenge of context. Studies in Higher Education, 23(2), I91-206.

Breidenstein, A., Fahey, K., Glickman, C., \& Hensley, F. (20I2). Leading for powerful learning: A guide for instructional leaders. New York:Teachers College Press.

Britzman, D. (2003). Practice makes practice:A critical study of learning to teach (revised ed.). Albany, NY: State University of New York Press.

Bryk, A. S. (20I0). Organizing schools for improvement. Phi Delta Kappan, 9 I (7), 23-30.

Bryk, A. S., \& Schneider, B. (2002). Trust in schools: A core resource for improvement. New York, NY: Russell Sage Foundation.

Bullough, R., Knowles, J.G., \& Crow, N. (199I). Emerging as a teacher. London: Routledge.

Bullough, Jr., R.V., \& Stokes, D. K. (1994). Analyzing personal teaching metaphors in preservice teacher education as a means for encouraging professional development. American Educational Research Journal, 3 I (I), 197-224.

Burke,W., Marx, G. E., \& Berry, J. E. (20I I). Maintaining, reframing, and disrupting traditional expectations and outcomes for professional development with critical friends groups (CFGs). Teacher Educator, 46(I), 32-52.

Calderhead, J. (1989). Reflective teaching and teacher education. Teaching \& Teacher Education, 5(I), 43-5I.

Calderhead, J. (1992). The role of reflection in learning to teach. In L.Valli (Ed.), Reflective teacher education: Cases and critiques (pp. 139-146). Albany, NY: State University of New
York Press.

Calderhead, J., \& Robson, M. (199I). Images of teaching: Student teachers' early conceptions of classroom practice. Teaching and Teacher Education, 7, I-8.

Calderwood, P. E., Mazza, M.A., Clarke,A., Favano, A. B., Jean-Guilluame, V., McNeill, D., \& Stenerson, C. (2008). The conversation of critical practice: Pre-service teachers as educators for social justice. International Journal for the Scholarship of Teaching and Learning, 2(1), Article 16.Available at: https://doi.org//0.20429/ijsotl.2008.020 I I6

Capers, M. (2004). Teaching and shared professional practice:A history of resistance; a future dependent on its embrace. In S. M. Hord (Ed.), Learning together leading together: Changing schools through professional learning communities (PP. I5I162). New York: Teachers College Press and Oxford, $\mathrm{OH}$ : National Staff Development Council.

Christensen, L. (2017). Reading, writing, and rising up:Teaching about social justice and the power of the written word $\left(2^{\text {nd }}\right.$ ed.). Milwaukee,Wl: Rethinking Schools.

Clandinin, D. J., \& Connelly, F. M. (2000). Narrative inquiry: Experience and story in qualitative research. San Francisco, CA: Jossey-Bass.

Cochran-Smith, M. (20I2). A tale of two teachers: Learning to teach over time. Kappa Delta Pi, 48, 108-122.

Costa,A. L., \& Kallick, B. (1993). Through the lens of a critical friend. Educational Leadership, 5 I (2), 49-5I.

Creswell, J.W. (2007). Qualitative inquiry \& research design (2 ${ }^{\text {nd }}$ ed.). Thousand Oaks, CA: Sage Publications.

Dana, N. F. (20I3). Digging deeper into action research:A teacher inquirer's field guide. Thousand Oaks, CA: Corwin.

Dana, N. F., \& Yendol-Hoppey, D. (2008). The reflective educator's guide to professional development: Coaching inquiry-oriented learning communities. Thousand Oaks, CA: Corwin Press.

Danielson, C. (1996). Enhancing professional practice:A framework for teaching. Alexandria,VA:The Association for Supervision and Curriculum Development.

Darling-Hammond, L., \& Bransford, J. (Eds.). (2005). Preparing teachers for a changing world:What teachers should learn and be able to do. New York: John Wiley \& Sons.

Delpit, L. (1993). The politics of teaching literate discourse. In T. Perry \& J.W. Fraser (Eds.), Freedom's plow:Teaching in multicultural classrooms (pp. 285-295). New York: Routledge.

Dewey, J. (1933). How we think. Boston, MA: D. C. Heath \& Co.

DuFour, R. (2007). Professional learning communities:A bandwagon, an idea worth considering, or our best hope for High levels of learning? Middle School Journal, 39(I), 4-8.

DuFour, R., DuFour, R., Eaker, R., \& Karhanek, G. (2004). Whatever it takes: How professional learning communities respond when kids don't learn. Bloomington, IN: National Educational Service.

DuFour, R., \& Eaker, R. (1998). Professional learning communities at work: Best practice for enhancing student achievement. Bloomington, IN: Solution Tree.

DuFour, R., Eaker, R., \& DuFour, R. (2005). Closing the knowing-doing gap. In R. DuFour, R. Eaker, \& R. DuFour (Eds.), On Common ground:The power of professional learning communities (pp. 225-254). Bloomington, IN: National Education Service.

Elmore, R. F. (2000). Building a new structure for school leadership.American Educator, 23(4), 6- I3. 
Fahey, K., \& Ippolito, J. (20I4). Towards a theory of critical friends group. School Reform Initiative.

Fendler, L. (2003). Teacher reflection in a hall of mirrors: Historical influences and political reverberations. Educational Researcher, 32(3), 16-30.

Flessner, R. (2012) Addressing the research/practice divide in teacher education. Action in Teacher Education, 34(2), I59I7I, DOI: I0.1080/0I626620.20I2.677739

Flessner, R. (2014). Revisiting reflection: Utilizing third spaces in teacher education. The Educational Forum, 78(3), 23 I-247. DOI: I0.1080/00131725.2014.9127||

Flessner, R., Miller, G. R., Patrizio, K. M., \& Horwitz, J. R. (20I2). Agency through teacher education: Reflection, community, and learning. New York: Rowman \& Littlefield Publishers.

Foster, D. (20I5). Private journals versus public blogs: The impact of peer readership on low-stakes reflective writing. Teaching Sociology, 43(2), I04-I I 4.

Francis, D. (1995). The reflective journal:A window to preservice teachers' practical knowledge. Teaching and Teacher Education, I I (3), 229-24I.

Franzak, J. K. (2002). Developing a teacher identity: The impact of critical friends practice on the student teacher. English Education, 34(4), 258-280.

Glesne, C. (2006). Becoming qualitative researchers:An introduction (3rd edition). Boston, MA. Pearson Education, Inc.

Gore, J. M., \& Zeichner, K. M. (199I). Action research and reflective teaching in preservice teacher education:A case study from the United State. Teaching and Teacher Education, 7(2), II9-136.

Griffith, M., \& Tann, S. (1992). Using reflective practice to link personal and public theories. Journal of Education for Teaching, I8(I), 69-84.

Hatton, N., \& Smith, D. (1995). Reflection in teacher education: Towards definition and implementation. Teaching and Teacher Education, I I ( I), 33-49.

Ippolito, J., \& Pomerantz, F. (20I4). Protocols as essential tools for literacy professional learning communities in the common core era. Massachusetts Reading Association Primer, 42(2), 44-5I.

Jones, M., \& Ryan, J. (2014). Learning in the practicum: Engaging pre-service teachers in reflective practice in the online space. Asia-Pacific Journal of Teacher Education, 42(2), I32146.

Kagan, D. M. (1992). Professional growth among preservice and beginning teachers. Review of Educational Research, 62(2), 129-169.

King, J. E. (199I). Dysconscious racism: Ideology, identity, and the miseducation of teachers. The Journal of Negro Education, 60(2), I33-146.

Knowles, J. G. (1992). Models for understanding pre-service and beginning teachers' biographies: Illustrations from case studies. In I. F. Goodson (Ed.) Studying Teachers' Lives (pp. 99152). New York: Teachers College Press.

Lakoff, G. \& Johnson, M. (1980/2003). Metaphors we live by. Chicago, IL: University of Chicago Press.

Law, B. (2005). Creating moral schools: The enabling potential of critical friends groups. Educational Horizons, 84(I), 53-57.

Lee, H.J. (2005). Understanding and assessing preservice teachers' reflective thinking. Teaching and Teacher Education, 21 , 699-7I5.
Lewison, M., Flint, A. S., \& Van Sluys, K. (2002). Taking on critical literacy:The journey of newcomers and novices. Language Arts, 79(5), 382-392.

Lincoln, Y. S., \& Guba, E. G. (1985). Naturalistic inquiry. Newbury Park, CA: Sage.

Liston, D. P., \& Zeichner, K. M. (1990). Reflective teaching and action research in preservice teacher education. Journal of Education for Teaching, I6(3), 235-254.

Liston, D. P., \& Zeichner, K. M. (I99I). Teacher education and the social conditions of schooling. New York: Routledge.

Liu, K. (20I5). Critical reflection as a framework for transformative learning in teacher education. Educational Review, 67(2), 135-157.

Lortie, D. C. (1975/2002). Schoolteacher:A sociological study (2 $2^{\text {nd }}$ ed). Chicago: University of Chicago Press.

Marshall, J. ( I98I). Making sense as a personal process. In P. Reason \& J. Rowan (Eds.), Human inquiry (pp. 395-399). New York, NY:Wiley.

McDonald, D., \& Kahn, M. (20I4). So, you think you can teach? Reflection processes that support pre-service teachers' readiness for field experiences. International Journal for the Scholarship of Teaching and Learning, 8(2), Article 18, I-34.

McLaughlin, M., \& Talbert, J. (2006). Building school-based teacher learning communities: Strategies to improve student achievement. New York:Teachers College Press.

Merriam, S. B. (2007). Case study research in education:A qualitative approach ( $2^{\text {nd }}$ ed.). San Francisco: Jossey-Bass.

Mezirow, J. (2000). Learning as transformation: Critical perspectives on a theory in progress. San Francisco, CA:The Jossey-Bass Higher \& Adult Education Series.

Miller, sj. (20I5). A queer literacy framework promoting (a)gender and (a)sexuality self-determination and justice. English Journal, 104(5), 37-44.

Mindrich, D., \& Lieberman,A. (20I2). Building a learning Community: A tale of two schools. Stanford, CA: Stanford Center for Opportunity Policy in Education.

Mishler, E. G. (1986). Research interviewing. Cambridge, MA: Harvard University Press.

Mishler, E. G. ( 1999). Storylines: Craftartists' narratives of identity. Cambridge, MA: Harvard University Press.

Munby, H., \& Russell, T. (1990). Metaphor in the study of teachers' professional knowledge. Theory into Practice, 29(2), II6-I2I.

Myers, J. (20/2). Lesson study as a means for facilitating preservice teacher reflectivity. International Journal for the Scholarship of Teaching and Learning, 6(I), Article I5, I-2I.Available at: https://doi.org/10.20429/ijsotl.2012.060I I5

National Council for the Accreditation of Teacher Education. (20I0). Transforming teacher education through clinical practice: A national strategy to prepare effective teachers, Washington, DC:Author.

National School Reform Faculty. (20I2). Self-guided tour of critical friends groups. Bloomington, IN: NSRF National Center.

Nieto, S. (2000). Placing equity front and center: Some thoughts on transforming teacher education for a new century. Journal of Teacher Education, 5 I (3), I80- 187.

Norman P.J., Goaian, K., \& Hooker, H. (2005). Professional development schools and critical friends groups: Supporting student, novice and teacher learning. The New Educator, I (4), 273-286. doi: I0.1080/I5476880500276793 
Osterman, K. \& Kottkamp, R. (2004). Reflective practice for educators: Professional development to improve student learning. New York: Skyhorse Publishing.

Patton, M. Q. (20I5). Qualitative research \& evaluation methods: Integrating theory and practice ( $4^{\text {th }}$ ed.). Thousand Oaks, CA: Sage Publications, Inc.

Pedro, J.Y. (2005). Reflection in teacher education: Exploring pre-service teachers' meanings of reflective practice. Reflective Practice, 6(I), 49-66.

Pultorak, E. G. (1996). Following the developmental process of reflection in novice teachers:Three years of investigation. Journal of Teacher Education, 47(4), 283-291.

“River City University.” (20।4). Fast Facts. Undisclosed website. Rodgers, C. (2002). Defining reflection:Another look at John Dewey and reflective thinking. Teachers College Record, 104(4), 842-866.

Schön, D.A. (1983). The reflective practitioner: How professionals think in action. New York: Basic Books.

Seidman, I. (2006). Interviewing as qualitative research:A guide for researchers in education and the social sciences ( $3^{\text {rd }}$ ed.). New York, NY:Teachers College Press.

Shenton, A. K. (2004). Strategies for ensuring trustworthiness in qualitative research projects. Education for Information, 22(2), 63-75.

Shulman, L. S., \& Shulman, J. H. (2004). How and what teachers learn: a shifting perspective. Journal of Curriculum Studies, 36(2), 257- 27I. doi: I0.I080/0022027032000I48298

Solomon, J. (1987). New thoughts on teacher education. Oxford Review of Education, 13(3), 267-74.

Sparks-Langer, G. M. ( 1992). In the eye of the beholder: Cognitive, critical, and narrative approaches to teacher reflection. In L.Valli (Ed.), Reflective teacher education: Cases and critiques (pp. 147-160). Albany, NY: State University of New York Press.

Stake, R. (1995). The art of case study research. Thousand Oaks, CA: Sage Publications, Inc.

Sturgill, A., \& Motley, P. (20I4). Methods of reflection about service learning: Guided vs. free, dialogic vs. expressive, and public vs. private. Teaching \& Learning Inquiry, 2(I), 8I-93.

Tabachnick, B. R., \& Zeichner, K. M. (1991). Issues and practices in inquiry-oriented teacher education. London: Falmer Press.
Tannebaum, R. P. and Cridland-Hughes, S.A. (2015) Preservice social studies teachers' conceptions of and experiences with discussion as a pedagogical approach:A case study. International Journal for the Scholarship of Teaching and Learning, 9(2), Article 10.Available at: https://doi.org/ I0.20429/ ijsotl.2015.090210

U.S. Census Bureau. (20I0). Quick facts. Retrieved from https:// www.census.gov/quickfacts/fact/table/US/PST0452I 7

Valli, L. (1992). Reflective teacher education: Cases and critiques. Albany, NY: State University of New York Press.

Valli, L. (1993). Reconsidering technical and reflective concepts in teacher education. Action in Teacher Education, $X V(2)$, 35-44.

Van Manen, M. (1977). Linking ways of knowing with ways of being practical. Curriculum Inquiry, 6, 205-228.

Yin, R. K. (2017). Case study research and application: Design and methods ( $6^{\text {th }}$ ed.). Thousand Oaks, CA: Sage Publications.

Yost, D. S., Sentner, S. M., \& Forlenza-Bailey, A. (2000). An examination of the construct of critical reflection: Implications for teacher education programming in the $2 \mathrm{I}^{\text {st }}$ century. Journal of Education, 5 I (I), 39-49.

Zeichner, K. M. (1992). Conceptions of reflective teaching in contemporary U.S. teacher education program reforms. In L.Valli (Ed.), Reflective teacher education: Cases and critiques (pp. I6I-I73).Albany, NY: State University of New York Press.

Zeichner, K. M. (1996). Teachers as reflective practitioners and the democratization of school reform. In K. Zeichner, S. Melnick, \& M. L. Gomez (Eds.), Currents of reform in preservice teacher education (pp. 199-2।4). New York:Teachers College Press.

Zeichner, K. M. (2007). Professional development schools in a culture of evidence and accountability. School University Partnerships, I(I), 9-I7.

Zeichner, K. M. (2008). A critical analysis of reflection as a goal for teacher education. Educacao \& Sociedade, 29(103). Accessed 16 July 20 I7: http://www.scielo.br/scielo.php?pid=S0 I0 |-733020080002000 I 2\&script=sci_arttext\&tlng=en

Zeichner, K. M., \& Liston, D. P. (20।3). Reflective teaching:An introduction $\left(2^{\text {nd }}\right.$ ed. $)$. New York:Taylor \& Francis. 


\section{APPENDIX A Reflective Teaching Entry Assignment Description}

\section{Assessment Criteria and Description of Expectations}

In terms of criteria for evaluation, high quality journal entries (above and beyond "proficient") contain elements of summary, analysis, and critical reflection (e.g., raising questions, interrogating assumptions, using dialogue, exposing vulnerability, taking personal and intellectual risks, exploring a curricular and/or societal dilemma, integrate an external resource, consider moral/political/ethical dimensions). (InTASC 9)

In addition to your name and the dates being reflected upon, each entry should contain the following labeled/discernable headings:

- Summary

- Analysis/Reflection

- Health \& Wellness

(I) Summary of activities and interactions at field site. Summaries should focus on aspects related to content/curriculum AND observations on the occurrences of literacy (practices and events), such as but not limited to reading, writing, speaking, listening, creating, interpreting, and performing. In addition to explicit connections to content and literacy standards, summaries should make explicit other connections to topics discussed in class(es). Some guiding prompts/questions for the summary include:

- What have you been doing? What activities did you participate in, direct, or assist?

- What kinds of interactions have you had with students, staff, and others? Have you been "off your seat and on your feet?"

- Describe the nature of any co-teaching that you have engaged in (parallel teaching, station teaching, supplemental teaching, team-teaching, etc.)?

- What have you been learning about teaching/teachers, learning/learners, yourself, your content area, and literacy in your content area?

- What are some teaching practices that you are observing and/or engaging in? How are the students responding to these practices?

- What kinds of connections are you making between conversations in class and observations in the field?

- What kinds of small-scale accomplishments are you currently reveling in? Or what kinds of obstacles (e.g. conflict between personal identity and professional identity) are you currently navigating?

- Describe the content of any feedback you receive from your students, mentor teacher(s), and/or others.

- $\quad$ Speak to any updates related to meeting Teaching and/or Content Area standards this week

(2) Analysis \& Reflection on experiences related to course topics, such as language and literacy apprenticeship, sociocultural contexts of literacy and learning, disciplinary literacy, authentic assessment, and critical literacy. The analysis section of the reflection should strive toward equity literacy, or your ability to recognize biases and inequities (subtle and overt) in classroom/school materials, classroom/school interactions, and classroom/school policies. In other words, you will be turning ordinary events into opportunities for critique and questioning. Plan your analysis and reflection with the four traditions of reflective practice in mind: Conservative (content-focused), Progressive (child-centered), Social Justice (context-centered), and Spiritual (contemplative-centered). Collect stories from your field site and reflect on the following questions as you choose one that is particularly interesting in relation to course topics:

- What happened? Choose a story that strikes you as particularly poignant. Write it succinctly.

- Why did it happen? Fill in enough of the context to give the story meaning. Answer the question in a way that makes sense to you.

- What might it mean? Recognizing that there is no one answer is an important step. Rather than locating "the problem" as located within an individual, consider possible structural sources for the event(s) (e.g., gender bias, classism, sexism, racism, ableism, homophobia, poverty, etc.). Explore multiple perspectives and possible meanings rather than determine the meaning.

- What are the implications for practice? Consider how your practice might change given any new understandings that have emerged from the earlier steps. What might be some implications, for example, for assigning homework, communicating with families, considering levels of access to resources, and for cultivating an environment concerned with bias and inequities?

(3) Health and Wellness: Teaching requires that we attend to our physical and mental health and well-being. How are you doing in terms of balancing the mind and body, practicum/school/work/social life, professional/personal identity? What did you do to maintain your health and wellness during this time? Or, what are some plans that you are making to maintain your physical and emotional well-being? 


\section{APPENDIX B Interview Protocol}

\section{Background Information}

- Tell me a little about your background and any significant events from your lived experiences that have shaped who you are as a person.

- $\quad$ Tell me about your decision to pursue teaching as a potential career.

- If at all, how has your understanding of the term "reflection" changed/evolved over the course of this semester?

\section{Field Experience}

- Tell me a little bit about your field experience placement this semester

\section{Reflective Teaching Journal}

- Did you find it valuable to maintain the reflective teaching journal?

- Tell me a little bit about your initial reflective teaching journals.

- Did maintaining a reflective teaching journal help you to become more reflective about your teaching or the teaching profession?

- What helped/aided you in reflecting on your practice(s) during this past semester (e.g., readings, conversations, writing, activities)?

\section{Critical Friends Group}

- Tell me a little bit about the role of your "critical friends group"

\section{Critical Reflection}

- What does it mean to be a critically reflective practitioner?

- If at all, how has the "critical friends group" influenced your thinking about teaching and learning?

- What experiences or critical moments have had the most significant impact on how you think of yourself and your role as a future teacher who is critically reflective? 